\title{
TRPV2 Enhances Axon Outgrowth through Its Activation by Membrane Stretch in Developing Sensory and Motor Neurons
}

\author{
Koji Shibasaki, ${ }^{1,2,3,5}$ Namie Murayama, ${ }^{2,3}$ Katsuhiko Ono, ${ }^{2,3,4}$ Yasuki Ishizaki, ${ }^{5}$ and Makoto Tominaga ${ }^{1,2,3}$ \\ ${ }^{1}$ Section of Cell Signaling, Okazaki Institute for Integrative Bioscience, National Institutes of Natural Sciences, Okazaki 444-8787, Japan, ${ }^{2}$ National Institute \\ for Physiological Sciences and ${ }^{3}$ Department of Physiological Sciences, The Graduate University for Advanced Studies, Okazaki 444-8585, Japan, \\ ${ }^{4}$ Department of Biology, Kyoto Prefectural University of Medicine, Kyoto 603-8334, Japan, and ${ }^{5}$ Department of Molecular and Cellular Neurology, Gunma \\ University Graduate School of Medicine, Maebashi 371-8511, Japan
}

Thermosensitive TRP (thermo TRP) channels are well recognized for their contributions to sensory transduction, responding to a wide variety of stimuli including temperature, nociceptive stimuli, touch, and osmolarity. However, the precise roles for the thermo TRP channels during development have not been determined. To explore the functional importance of thermo TRP channels during neural development, the temporal expression was determined in embryonic mice. Interestingly, TRPV2 expression was detected in spinal motor neurons in addition to the dorsal root ganglia from embryonic day 10.5 and was localized in axon shafts and growth cones, suggesting that the channel is important for axon outgrowth regulation. We revealed that endogenous TRPV2 was activated in a membrane stretchdependent manner in developing neurons by knocking down the TRPV2 function with dominant-negative TRPV2 and TRPV2-specific shRNA and significantly promoted axon outgrowth. Thus, for the first time we revealed that TRPV2 is an important regulator for axon outgrowth through its activation by membrane stretch during development.

\section{Introduction}

In mammals, TRP channels now comprise six related protein families (TRPC, TRPV, TRPM, TRPA, TRPML, and TRPP) and are well recognized for their contributions to sensory transduction (Damann et al., 2008; Talavera et al., 2008). Among them, TRPV2 was originally cloned as a heat sensor and is well known to be activated by very high temperature $\left(>52^{\circ} \mathrm{C}\right.$ ) (Caterina et al., 1999). TRPV2 is expressed in middle- to large-diameter neurons, most of which are myelinated $\mathrm{A} \delta$ fibers in the adult, while another heat sensor TRPV1 and two cold sensors (TRPA1 and TRPM8) are expressed in C fibers, small-diameter neurons (Caterina et al., 1997; McKemy et al., 2002; Peier et al., 2002; Story et al., 2003; Jordt et al., 2004). These interesting expression

\footnotetext{
Received Nov. 24, 2009; revised Jan. 9, 2010; accepted Feb. 5, 2010.

This work was supported by Grants-in-Aid for Scientific Research (KAKENHI 20700309 and Shin-Gakujyutsu 21200012) from the Ministry of Education, Culture, Sports, Science and Technology, by The Uehara Memorial Foundation, by The Ichiro Kanehara Foundation, by a TFT research grant to K.S., and by support from the Ministry of Education, Culture, Sports, Science and Technology to M.T. We thank Drs. M. Sravan, K. Togashi, N. Fukuta (Okazaki Institute for Integrative Bioscience, Okazaki), K. Watanabe (Kumamoto University), and Shu-Ichi Watanabe (Saitama Medical University) for technical assistance and Drs. Y. Kubo and K. Ikenaka (National Institute for Physiological Sciences, Okazaki) for discussion. The plasmids were kindly provided by Dr. Q. Ma (Harvard University) and Dr. C. Cepko (Harvard University). The sequence for the dominant-negative TRPV2 was kindly provided by Drs. I. Kojima and M. Nagasawa (Gunma University). The pCAGIG plasmid was kindly provided by Dr. C. Cepko (Harvard University). The monoclonal antibody Islet-1, developed by T. Jessell, was obtained from the Developmental Studies Hybridoma Bank maintained by the University of lowa Department of Biological Sciences.

Correspondence should be addressed to either of the following: Koji Shibasaki, Department of Molecular and Cellular Neurology, Gunma University Graduate School of Medicine, Maebashi 371-8511, Japan, E-mail: shibasaki@ gunma-u.ac.jp; or Makoto Tominaga, Section of Cell Signaling, Okazaki Institute for Integrative Bioscience, National Institutes of Natural Sciences, 0kazaki 444-8787, Japan, E-mail: tominaga@nips.ac.jp.

DOI:10.1523/JNEUROSCI.5830-09.2010

Copyright $\odot 2010$ the authors $\quad 0270-6474 / 10 / 304601-12 \$ 15.00 / 0$
}

patterns suggest that the thermo TRP channels identify specific neuronal subpopulations (which are partly classified by specific neurotrophic receptors) in the adult dorsal root ganglion (DRG) and exert channel functions for pain and/or thermosensation.

Expression patterns of thermo TRP channels are well studied in the adult DRG. However, their expression during development is poorly characterized (Tamura et al., 2005; Hjerling-Leffler et al., 2007). Furthermore, it is unclear when channel expression starts in the developing DRG and spinal cord. In addition, specific roles for thermo TRP channels during development have yet to be defined. Identification of thermo TRP channel expression patterns during development would be important because it is well documented that some ion channels/receptors have two distinct and vital roles in embryonic and adult stages. For example, voltage-gated potassium channels regulate membrane excitabilities in adult neurons (Trimmer, 1998), whereas the channels have different roles during neural development such as regulation of cell proliferation, axon outgrowth, and neuronal maturation (Shibata et al., 2000; Pollock et al., 2002; Shibasaki et al., 2004; Liebau et al., 2006). It is also known that NMDA receptors regulate neural cell migration during development while their common role in adults is to act as key regulators for neural excitation (Nakanishi, 1992; Komuro and Rakic, 1993). These facts suggest that thermo TRP channels might specifically regulate cell proliferation, migration or axon outgrowth during development. Thus, it is highly possible that thermo TRP channels regulate axon outgrowth in developing neurons. In this report, we examined the expression and specific roles for TRPV2 in the developing sensory and motor neurons. 


\section{Materials and Methods}

Animals. ICR strain mice were used. Embryos were considered as embryonic day 0.5 (E0.5) at noon on the day at which vaginal plugs were observed. Fertilized chicken eggs were purchased from Gen, and the eggs were cultured for $3 \mathrm{~d}$ at $38.5^{\circ} \mathrm{C}$ until they become embryos at Hamburger and Hamilton stage (HH) 10-14. All animal care and procedures were performed according to National Institutes of Health, National Institute for Physiological Sciences, and Gunma University guidelines.

In situ hybridization. Digoxigenin-labeled antisense/sense probes were used for in situ hybridization. A fragment of mouse TRPV2 cDNA was obtained by PCR ( $5^{\prime}$-mTRPV2 and 3' -mTRPV2 primer sets: $5^{\prime}$-CTGGAGATGAGAGTGGTACCT-3', and 5'-TCTACTGGTACCGTGTGTGTCTA-3'). The 492 bp fragment was subcloned into pBluescriptSKII $(+)$ BamHI and XbaI sites. TRPV1 and TRPM8 in situ plasmids (Chen et al., 2006) were kindly provided by Dr. Q. Ma (Harvard University, Cambridge, MA). After linearizing the plasmid (antisense: $\mathrm{BamHI}$, sense: $\mathrm{XbaI}$ ), digoxigenin-labeled antisense/sense probes were synthesized by RNA polymerase (antisense: T3 RNA polymerase, sense: T7 RNA polymerase). Detection of mRNA on cryosectioned tissues $(14 \mu \mathrm{m})$ was performed by nitro blue tetrazolium chloride/ 5-bromo-4-chloro-3-indolyl phosphate through alkaline phosphataseconjugated anti-digoxigenin antibody (Roche).

Immunohistochemical analysis. Immunohistochemistry and in situ hybridization were performed as previously described (Shibasaki et al., 2007a,b). The following antibodies were used: rabbit polyclonal antiTRPV2 antibody (1:200, generated in our laboratory; Tamura et al., 2005), mouse anti-Ki67 (1:200, clone B56, PharMingen), mouse monoclonal anti-neurofilament M (1:500, culture supernatant, IC8), and sheep anti-Chx10 (1:200, Ex $\alpha$ ). The following mouse monoclonal antibodies were also used and obtained from the Developmental Studies Hybridoma Bank: anti-BrdU (1:500), anti-Islet-1 (1:500), anti-Hb9 (1: $200)$, anti-En 1 (1:50), and anti- $\beta$-tubulin (1:500, Sigma). To evaluate the outgrowth of DRG axons, the axon area outside the DRG explant core region was measured using ImageJ software or IP-Lab software. Data were statistically analyzed using Student's unpaired $t$ test and ANOVA.

For bromodeoxyuridine (BrdU, Sigma) labeling experiments, pregnant females were injected intraperitoneally with $100 \mu \mathrm{g} \mathrm{BrdU/g}$ body weight $1 \mathrm{~h}$ before killing. Embryo processing and BrdU labeling were performed as previously described (Shibasaki et al., 2007b). To detect apoptotic cells, terminal deoxynucleotidyl transferase-mediated dUTP nick end labeling (TUNEL) staining was performed with a commercial kit (Roche).

Cultivation of dissociated embryonic DRGs/motor neuron cells and embryonic DRG explants. Embryonic mouse DRGs or motor neurons were prepared using a modified protocol originally designed for cultivation of the mouse hippocampus (Shibasaki et al., 2007a). In brief, DRGs or the ventral half of spinal cords were dissected from E12.5 embryos and dissociated using mechanical trituration. Cells were plated on poly-Dlysine-coated coverslips ( $15 \mathrm{~mm}$ round, Assistant) at a final density of $3-5 \times 10^{5}$ cells/coverslip in Neurobasal medium (Invitrogen) with B27 supplement (Invitrogen), NGF (10 ng/ml, Sigma), NT-3 (10 ng/ml, Calbiochem), and penicillin/streptomycin (1:250, Invitrogen). After $12 \mathrm{~h}$, coverslips were immersed in fresh Neurobasal medium with B27 supplement, NGF and NT-3. To prevent overgrowth of glia and fibroblasts, cultures were treated with cytosine arabinoside ( $5 \mu \mathrm{M}$; Calbiochem). Embryonic DRG explant cultures were also performed from E12.5 embryos. Dissected DRGs were put on poly-D-lysine-coated coverslips in Neurobasal medium with B27 supplement, NGF and NT-3. After 12 h, coverslips were immersed in fresh Neurobasal medium with B27 supplement, NGF, and NT-3 [with cytosine arabinoside $(5 \mu \mathrm{M})$ ]. To examine the effect of low calcium on TRPV2-dependent axon outgrowth, we used low- $\mathrm{Ca}^{2+}$ DMEM ( $0.15 \mathrm{~mm}^{2}$ low $\mathrm{Ca}^{2+}$ ) or regular DMEM (2 mM normal $\mathrm{Ca}^{2+}$ ) with $10 \%$ fetal bovine serum, NGF, NT-3, and penicillin/streptomycin instead of the above-described culture medium.

Application of cyclic stretch. Membrane stretch was applied by a computer-controlled stepping motor machine (STB-150, STREX) as previously described (Naruse et al., 1998). Dissociated DRG or ventral spinal cord cells were transferred onto a $4 \mathrm{~cm}^{2}$ silicon chamber coated with $50 \mu \mathrm{g} / \mathrm{ml}$ fibronectin at a density of $3 \times 10^{4}$ cells $/ \mathrm{cm}^{2}$. After $2 \mathrm{~d}$, the silicon chamber was attached to a stretching apparatus that was driven by a computer-controlled stepping motor. Using this system, quantitative and uniform stretch $(+2.8 \%$ length for $15 \mathrm{~s})$ was applied to the cells.

In vitro and in ovo electroporation. Electroporation was performed by a modified protocol as previously described (Matsuda and Cepko, 2004; Nakahira et al., 2006). Embryonic DRGs or the ventral half of spinal cords (at E12.5) were dissociated using mechanical trituration from anesthetized embryos by chilling on ice. DNA solutions $(5 \mu \mathrm{g} / \mu \mathrm{l})$ in PBS containing $0.1 \%$ fast green as a tracer were transferred to the electroporation chamber with dissociated DRG cells. Five square pulses $(33 \mathrm{mV})$ of $50 \mathrm{~ms}$ duration with $950 \mathrm{~ms}$ intervals were applied by a pulse generator, ECM830 (BTX).

In ovo electroporation was performed as described previously (Itasaki et al., 1999). Briefly, chicken eggs were windowed, and small amounts of EGFP-reporter plasmids were injected in the neural tube lumen in chick embryos at the HH $10-14$ with $0.05 \%$ fast green, and the injected DNA was unilaterally pulse electroporated $(35 \mathrm{mV}, 5$ times, $50 \mathrm{~ms}$ duration with $950 \mathrm{~ms}$ intervals). The window was sealed with adhesive tape and the eggs were returned to the incubator for further incubation.

Plasmids. All expression vector designs were based on the pCAGIG vector. The pCAGIG vector, which contains the IRES-EGFP cDNA under the control of the CMV enhancer and chick $\beta$-actin promoter, was a gift from Dr. C. Cepko [Harvard University, Cambridge, MA (Matsuda and Cepko, 2004)]. The full coding sequence for murine TRPV2 was obtained by reverse transcription PCR. Total RNA was prepared from the DRGs of adult ICR mice by using TRIzol reagent (Invitrogen). Total RNA $(1 \mu \mathrm{g})$ was converted to cDNA using SuperScriptII RNaseH (-) reverse transcriptase (Invitrogen). The coding regions of mouse TRPV2 were PCR amplified from cDNA with the following $5^{\prime}$-EcoRI-mTRPV2 and $3^{\prime}$-XhoI-mTRPV2 primer sets: $5^{\prime}$ ATGGAATTCATGACTTCAGCCTCCAACCCCCCAGC-3' ${ }^{\prime}$, and $5^{\prime}$-ATGCTCGAGTCAGTGGGACTGGAGGACCTGA-3'. The PCR product was subcloned into the pCAGIG vector at EcoRI and XhoI sites. Dominantnegative (DN) TRPV2 was generated based on the short-form TRPV2/ pEGFP-N2 (Nagasawa et al., 2007). Briefly, the TRPV2 channel-pore deleted mutant was generated by PCR with the following 5 '-EcoRI-DN TRPV2 and 3'-XbaI-DN TRPV2 primer sets: 5' -GGAATTCTTATGACCTCACCCTCCAGCTCTCCA- 3 ' , and 5'-GCTCTAGATCAGTTGGACTGGAGGAGCTGGAC- $3^{\prime}$. The PCR product was subcloned into pBluescriptSKII $(+)$, which had 2-cmyc tags before the EcoRI sites. The 2-cmyc-DN TRPV2 fragment was cut out by SalI and XbaI digestion, and the fragment was treated with T4 DNA polymerase to generate blunt ends. The DN-TRPV2 fragment was subcloned into pCAGIG (the EcoRI sites were blunt ended), and the sequence was verified. For TRPV2 knockdown, we used an RNA interference strategy. We designed short hairpin RNA (shRNA) by siRNA target finder (Ambion) and picked up the following target sequences: TRPV2-shRNA\#1, AACCTTCAGGATGGGGTCAAT; and TRPV2-shRNA\#2, AAGACCCTTCCCACCTTATCT. The scrambled control was designed corresponding to the first duplex of shRNA. The corresponding shRNA duplexes were synthesized and subcloned into pSilencer 1.0 vector (HindIII-EcoRI sites).

Fluorescent measurements and electrophysiology. Fura-2 fluorescence was measured by fura-2 AM (Invitrogen) in a standard bath solution containing the following (in mM): $140 \mathrm{NaCl}, 5 \mathrm{KCl}, 2 \mathrm{MgCl}_{2}, 2 \mathrm{CaCl}_{2}, 10$ HEPES, and 10 glucose, $\mathrm{pH}$ 7.4. The $340: 380 \mathrm{~nm}$ ratio was recorded. The standard bath solution for the patch-clamp experiments was the same as that used in fluorescence measurements. Pipette solution for whole-cell recordings contained the following (in $\mathrm{mM}$ ): $140 \mathrm{CsCl}, 0.5 \mathrm{EGTA}, 2 \mathrm{Mg}$ ATP, $2 \mathrm{~K}_{2}$-GTP, and 10 HEPES, pH 7.4. Whole-cell recording data were sampled at $10 \mathrm{kHz}$ and filtered at $5 \mathrm{kHz}$ for analysis (Axon 200B amplifier with pCLAMP software, Molecular Devices).

\section{Results}

\section{TRPV2 is expressed in developing DRG and spinal cord}

We first determined when TRPV2 is expressed using in situ hybridization in developing DRG and spinal cord sections from E9.5 to adult. Specificity of in situ probe was confirmed by comparison between antisense and sense probes (supplemental Fig. $1 A$, available at www.jneurosci.org as supplemental material) and by comparison between mRNA and protein expression (Figs. 


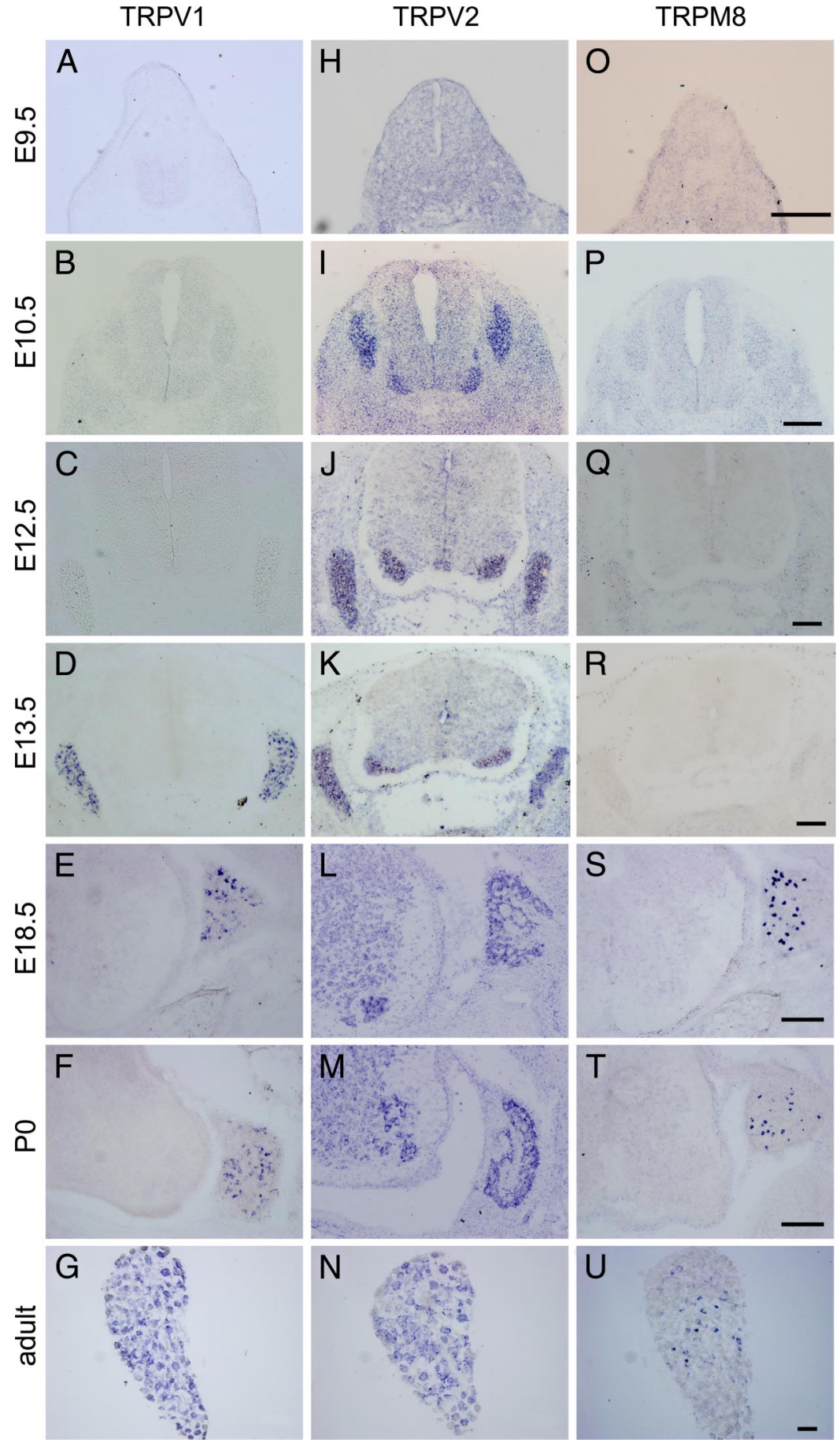

Figure 1. Time course of thermo TRP channel mRNA expression in the developing DRG and spinal cord. In situ hybridization analysis was performed in the spinal cord region of E9.5 to adult mice. $\boldsymbol{A}-\boldsymbol{N}$, Expression of TRPV1 $(\boldsymbol{A}-\boldsymbol{G})$ and TRPV2 $(\boldsymbol{H}-\boldsymbol{N})$ started at different time points (TRPV2, E10.5; TRPV1, E13.5). 0-U, TRPM8 expression was observed after E13.5. Expression of TRPV2 mRNA was observed both in the DRGs and spinal cord ventral horns $(I-M)$. Scale bars, $100 \mu \mathrm{m}$.

1,2). TRPV2 was not detected in the spinal cord at E9.5 (Fig. $1 H$ ), when neural crest cells (progenitors) tangentially migrate ventrally, forming the DRG. Interestingly, TRPV2 expression started in the ventral part of the spinal cord, in which motor neuron cell bodies are located, in addition to the DRG at E10.5 (Fig. 1I). Other TRP channels (TRPV1 and TRPM8) were not detected in the spinal cord at this time point (Fig. $1 B, P$ ). TRPV2 expression was sustained to E13.5 (Fig. $1 I-K$ ) in both the ventral spinal cord and DRG. These results imply that TRPV2 is expressed at specific times in the developing DRG and spinal cord.
TRPV1 expression started in the DRG by E13.5 (Fig. $1 A-D$ ). In contrast to TRPV2, TRPV1 expression was detected only in the DRG but not in the ventral spinal cord. TRPV1 expression was observed in specific cell types (Fig. $1 D$, small dot pattern) in the DRG at E13.5, in contrast to TRPV2 expression in a larger population in the DRG (Fig. $1 I-K$ ). TRPM8 expression was detected in a specific subpopulation of DRG cells at E18.5 (Fig. 1S), and continued through the adult (Fig. 1S$U)$. Similar to the TRPV1 expression pattern (Fig. 1D-F), TRPM8 was detected only in specific cell types of the developing DRG (Fig. 1S, T, small dots), and not in the ventral spinal cord (Fig. 1S,T). [TRPA1 expression was also assessed (our unpublished results).]

Judging from these results, TRPV2 (from E10.5) (Fig. 1I) was initially expressed more broadly in both developing DRG and ventral spinal cord. Interestingly, TRPV2-expressing cells decreased in number depending on the developmental stage (Fig. $1 I-N)$.

\section{TRPV2-expressing cells in spinal cord are restricted to motor neurons}

We next examined TRPV2 protein expression in the developing DRG and spinal cord (Fig. 2). We confirmed specificity of TRPV2 antibody by peptide absorption (supplemental Fig. $1 B$, available at www. jneurosci.org as supplemental material). Consistent with the mRNA expression pattern (Fig. $1 H-J$ ), TRPV2 protein was detected both in the DRG and spinal cord at E10.5, but not at E9.5 (Fig. $2 A^{\prime}, B^{\prime}$ ). TRPV2 protein was observed in the spinal cord dorsal horn, in which DRG axons project in addition to the DRG and ventral spinal cord (Fig. $2 B^{\prime}-F^{\prime}$ ), resulting in different staining patterns between mRNA (only in cell bodies) (Fig. $1 I-K$ ) and protein (axons and growth cones in addition to cell bodies) (Fig. $2 B^{\prime}-F^{\prime}$ ). Then, the cell types that expressed TRPV2 in the developing ventral spinal cord were examined by double-immunostaining with motor neuron-markers (Islet-1/2 and $\mathrm{Hb} 9$ ) or interneuron-markers (Chx10 and En1). Most TRPV2-positive cells coexpressed Islet- $1 / 2$ in the ventral spinal cord (Fig. $2 B^{\prime \prime \prime}, C^{\prime \prime \prime}$ ). Because TRPV2 is a membrane protein and Islet $1 / 2$ is a nuclear protein (transcription factor), Islet $1 / 2$ staining was surrounded by TRPV2 (Fig. 2b,c). These results suggest that TRPV2 is mainly expressed in developing motor neurons. To confirm this, expression of TRPV2 and Hb9 (another motor neuron marker) in the ventral spinal cord at E11.5 was compared. TRPV2 expression overlapped with $\mathrm{Hb} 9$ in the medial motor column of the ventral spinal cord, but not near the ventricular zone (Fig. 2 $\left.D^{\prime \prime \prime}, d\right)$. However, TRPV2 expression did not overlap with Chx10 (V2 interneurons) 
or En1 (V1 interneurons) in the ventral spinal cord at E11.5 (Fig. $2 E^{\prime \prime \prime}, F^{\prime \prime \prime}, e, f$ ), suggesting that TRPV2 is specifically expressed in developing motor neurons, but not in interneurons.

\section{Functional expression of the thermo}

TRP channels in the developing DRG

To confirm the developmental expression of thermo TRP channels (TRPV1, TRPV2, and TRPM8), we performed $\mathrm{Ca}^{2+}$-imaging experiments with fura- 2 in acutely dissociated DRG cells at different stages of development (E12.5, E14.5, and P0) (Fig. 3). In these experiments, $50 \mathrm{~mm} \mathrm{KCl}$ solution was applied for neuronal identification. To confirm channel activities, we applied known TRP channel agonists: $1 \mu \mathrm{M}$ capsaicin (CAP) for TRPV1 (Caterina et al., 1997), $300 \mu \mathrm{M}$ menthol for TRPM8 (McKemy et al., 2002) and $100 \mu \mathrm{m}$ probenecid (Prob) for TRPV2 (Bang et al., 2007). In agreement with the mRNA and protein expression patterns (Figs. 1, 2), we failed to detect CAPresponsive TRPV1-expressing cells at E12.5. However, we did observe two cell populations; one was Prob responsive TRPV2 expressing (88.6\%, indicated as blue), consistent with TRPV2 expression at this stage, and the other was Prob nonresponsive TRPV2 negative (11.4\%, indicated as red). At E14.5, we observed CAP-responsive TRPV1-expressing cells, which were never observed at E12.5. We generally observed three populations at E14.5. One was a non-menthol-responsive, CAP- and Prob-responsive (TRPV1- and TRPV2expressing) population (28.5\%, indicated as green) as described above, and the other two populations were the same as observed at E12.5 (only TRPV2-expressing cells, $62.4 \%$ and TRPV2-negative cells, 10.1\%). At P0, we observed a small menthol-responsive population which also responded to Prob (5.4\%, indicated as yellow) in addition to three populations observed at E14.5 (39.2\% for TRPV1- and TRPV2-expressing cells, $28.0 \%$ for TRPV2-expressing cells, and $27.4 \%$ for TRPV2-negative cells), suggesting that the thermo TRP channel expression pattern dynamically changed in a subset of DRG neurons depending on the developmental stage. This functional expression of thermo TRP channels (Fig. 3) perfectly parallels their mRNA and protein expression patterns (Figs. 1, 2).

\section{Physiological importance of thermo TRP channels during neural development}

The preceding experiments demonstrated that thermo TRP channels are expressed in the DRG and/or spinal motor neurons during embryonic development (Figs. 1-3). It has been well documented that thermo TRP channels act as temperature sensors, and some act as detectors for nociceptive stimuli as well (Woolf and Ma, 2007). Given the fact that mammalian embryos are kept in a constant temperature environment, thermo TRP channels might have other functions such as regulating developmental
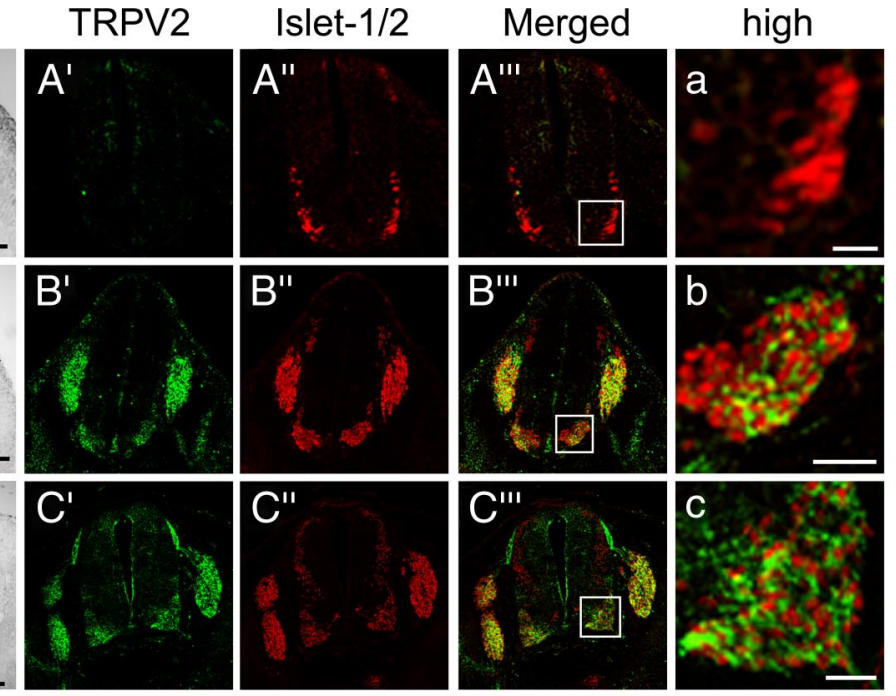

TRPV2
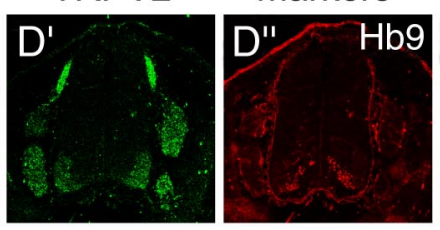

Merged
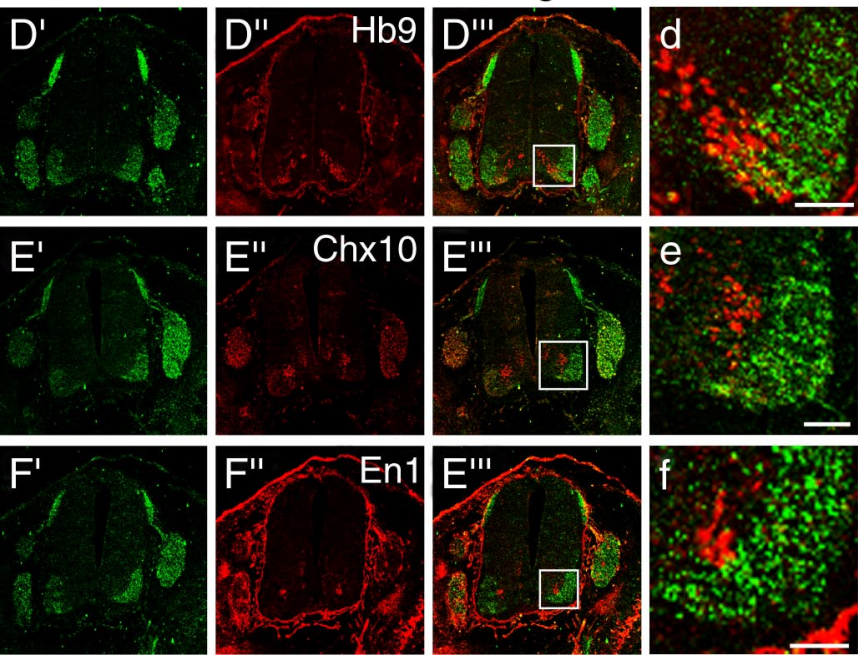

Figure 2. TRPV2 protein is expressed in developing motor neurons but not in interneurons. $\boldsymbol{A}-\boldsymbol{C}$, Comparison of TRPV2 expres$\boldsymbol{F}^{\prime}$, green) with each marker (Hb9, a motor neuron marker; Chx10, a V2 interneuron marker; En1, a V1 interneuron marker) $\left(\boldsymbol{D}^{\prime \prime}, \boldsymbol{E}^{\prime \prime}, \boldsymbol{F}^{\prime}\right.$, red) in the developing spinal cord at E11.5. $\boldsymbol{d}-\boldsymbol{f}$, Magnified images from the boxes in $\boldsymbol{D}^{\prime \prime}-\boldsymbol{F}^{\prime \prime}$, respectively. Scale bars, $100 \mu \mathrm{m}$.

processes. Therefore, we examined embryonic stage-specific events which might involve thermo TRP channels such as cell proliferation, apoptosis, cell migration, and neurite outgrowth.

We first examined whether TRPV2 is related to cell proliferation by double immunostaining with a cell proliferation marker, Ki67. We observed that some DRG cells were proliferating (Ki67-positive cells) at E14.5 (supplemental Fig. $2 A^{\prime}$, available at www.jneurosci.org as supplemental material). However, none of the TRPV2-positive cells expressed Ki67 (supplemental Fig. 2A", available at www.jneurosci.org as supplemental material). We also performed BrdU labeling of S-phase cells (Shibasaki et al., 2007b) in the DRG at E14.5. No expression of TRPV2 was observed in the BrdU-positive cells (supplemental Fig. $2 B^{\prime \prime}$, available at www.jneurosci.org as supplemental material). These results indicate that TRPV2 expression starts in postmitotic DRG cells. To confirm whether postmitotic neurons or other cells express TRPV2, we performed double-immunostaining of TRPV2 with Islet-1/2, a neuronal transcription factor (Shibasaki et al., 2007b). Most TRPV2-positive cells also expressed Islet-1/2 
A

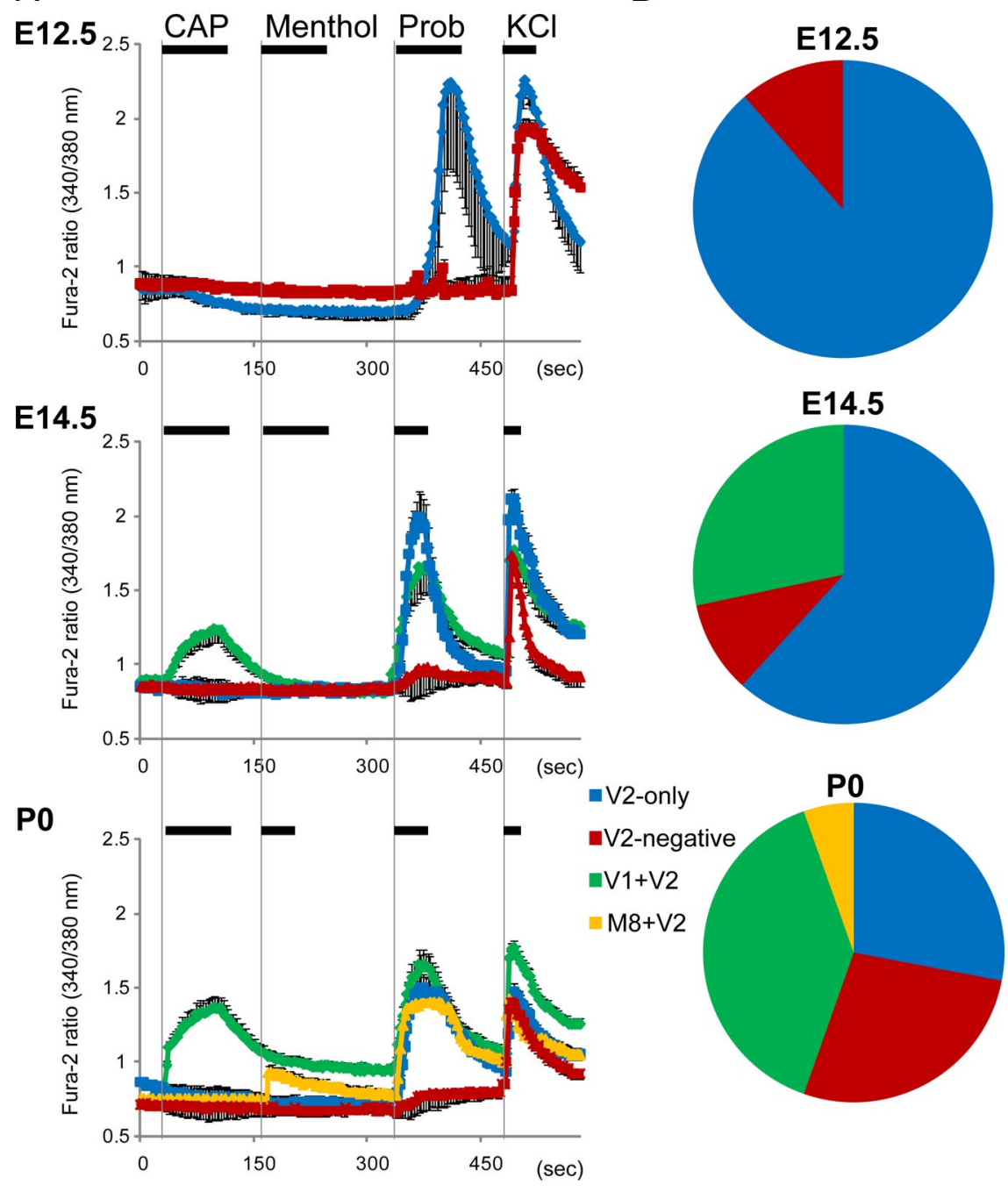

Figure 3. Responsiveness to indicated stimuli assessed by changes in cytosolic $\mathrm{Ca}^{2+}$ concentration in acutely dissociated DRG sensory neurons. CAP (1 $\mu$; ; for TRPV1), menthol (300 $\mu \mathrm{m}$; for TRPM8), or Prob (100 $\mu \mathrm{m}$; for TRPV2) was applied to dissociated DRG neurons (E12.5, E14.5 and P0) to measure TRPV1, TRPM8 or TRPV2 activity, respectively, by calcium imaging with fura-2. We applied $50 \mathrm{~mm} \mathrm{KCl}$ to identify neural populations in each experiment. $\boldsymbol{A}, \boldsymbol{B}$, After we quantified the intracellular calcium level, cell subtypes were classified depending on the response to each stimulus $(\boldsymbol{A})$. Then, the ratio of cell subtypes was calculated according to the results among $\mathrm{KCl}$-responder cells $(\boldsymbol{B})$.

(supplemental Fig. 2 $C^{\prime \prime}$, available at www.jneurosci.org as supplemental material), indicating that postmitotic neurons express TRPV2.

Although the TRPV2-positive neurons were the major population $(91.3 \%)$ in the developing DRG (supplemental Fig. 2, available at www.jneurosci.org as supplemental material), it should be noted that some Islet-1/2-positive neurons were TRPV2 negative (8.7\%) (supplemental Fig. 2C", arrowheads, available at www. jneurosci.org as supplemental material), indicating that some TRPV2-negative neurons are present in embryonic stages, consistent with $\mathrm{Ca}^{2+}$-imaging results (Fig. 3 ).

Next, we performed TUNEL staining to determine whether expression of embryonic TRPV2 is related to apoptosis. None of the TUNEL-positive apoptotic cells expressed TRPV2 in the DRG at E14.5 (supplemental Fig. 2 $D^{\prime \prime}$, available at www.jneurosci.org as supplemental material). The fact that TRPV2 is not colabeled with cell proliferative or apoptotic markers in the developing DRG prompted us to raise the possibility that the embryonic TRPV2 might regulate cell migration in the developing DRG.
This hypothesis seemed unlikely because DRG is formed by migrating neural crest cells from near the dorsal spinal cord, and thermo TRP channel expression in the tangential migrating cells near both sides of the spinal cord would be expected if the thermo TRP channels regulated cell migration. However, we did not detect any TRPV2 in migrating cells (Figs. 1, 2). Together, these results indicate that TRPV2 expression starts in postmigrating and postmitotic neurons in the DRG.

\section{TRPV2 is expressed in the entire developing DRG and motor neurons and promotes axon outgrowth}

The above results led us to consider that embryonic TRPV2 might regulate axon outgrowth because TRPV2 is expressed in DRG and motor neurons while these cells undergo long axon formation. We examined the cellular localization of TRPV2 in developing DRG and motor neurons. TRPV2 protein was observed in developing motor neurons, DRG and the spinal cord dorsal horn as described above (Fig. 2). TRPV2 expression in the spinal cord dorsal horn was colabeled with an antineurofilament $\mathrm{M}$ antibody at E12.5 (Fig. $4 A^{\prime \prime}$, arrowheads), suggesting that TRPV2 proteins accumulate in the dorsal horn. Pursuing that observation, we prepared dissociated DRG or ventral spinal cord (including motor neurons) cell cultures from E12.5 mouse embryos. First, we examined whether DRG neurons and/or glial cells expressed TRPV2 by colabeling with DRG neuron marker Islet-1/2. We found that only Islet-1/2-positive DRG neurons expressed TRPV2 in the culture at 2 DIV (supplemental Fig. 3, available at www.jneurosci.org as supplemental material) but not glial cells and fibroblasts, consistent with the in vivo results (Fig. 2; supplemental Fig. 2, available at www.jneurosci.org as supplemental material). TRPV2 proteins were detected in soma (Fig. $4 B$, arrows), in which TRPV2 was colabeled with nuclear protein Islet1/2 (Fig. $4 B^{\prime}, B^{\prime \prime}$, arrows), axon shafts, and growth cones $\left(4 B, B^{\prime \prime}\right.$, arrowheads). The signals in growth cones were distinguished by $\beta$ III-tubulin staining at 2 DIV (Fig. $4 C-C^{\prime \prime}$, arrowheads). Note that TRPV2 expression in growth cones was observed at the cell surface (Fig. $4 C^{\prime \prime}$, arrowheads), and TRPV2 proteins accumulated in some growth cones, which is consistent with the in vivo results (Fig. $4 A-A^{\prime \prime}$ ). Similar to DRG neurons, TRPV2 was detected in soma (Fig. $4 D$, arrow), axon shafts, and growth cones (Fig. $4 D$, arrowhead) of a motor neuron, which can be distinguished by Islet1/2 labeling (Fig. $4 D^{\prime}$ ). The fact that TRPV2 expression started at E10.5 when axon outgrowth was abundant suggests that TRPV2 may be involved in axon outgrowth. TRPV2 expression in developing growth cones (Fig. 4) suggests that TRPV2 might regulate axon outgrowth during DRG development. Therefore, we next examined whether TRPV2 activation changed axon outgrowth. We prepared DRG explant 
cultures from E12.5 mouse embryos and applied $100 \mu \mathrm{M}$ probenecid for $2 \mathrm{~d}$. Compared with the control (Fig. $4 E, 104.6 \pm$ $9.8 \%$ of axon area, $n=55$ in Fig. $4 G$ ), TRPV2 activation by probenecid significantly enhanced axon outgrowth (Fig. $4 F$, $104.6 \pm 9.8 \%$ of axon area, $n=86$ in Fig. $4 G)$, suggesting that TRPV2 is a positive regulator for axon outgrowth in developing neurons.

\section{TRPV2 is activated by membrane} stretch in developing neurons We searched for TRPV2 activators in developing neurons. Since it is expected that TRPV2 can be activated by membrane stretch (Muraki et al., 2003), we hypothesized that membrane stretch by axon outgrowth might activate TRPV2 endogenously. To confirm this hypothesis, we first prepared HEK293T cells expressing mouse TRPV2, and applied membrane stretch [102.8\% (length) for $15 \mathrm{~s}$ ] to the cells by a pulse-motor-driven stretch machine called as STREX (Mochizuki et al., 2009) during $\mathrm{Ca}^{2+}$-imaging experiments with fura-2. The membrane stretch-evoked increase in intracellular $\mathrm{Ca}^{2+}\left(\left[\mathrm{Ca}^{2+}\right]_{\mathrm{i}}\right)$ was observed only in the transfected (TRPV2expressing) cells (Fig. 5A), indicating that TRPV2 can be activated by weak membrane stretch. To further confirm the membrane stretch-activated properties of TRPV2 in native neurons, we prepared dissociated DRG neurons from E12.5 mouse embryos, and cultured them on fibronectin-coated silicon plates for $2 \mathrm{~d}$. Then, we applied membrane stretch by the STREX [102.8\% (length) for $15 \mathrm{~s}$ ] as described above. The $\left[\mathrm{Ca}^{2+}\right]_{\mathrm{i}}$ in embryonic DRG neurons increased in response to membrane stretch. The membrane stretch-evoked $\left[\mathrm{Ca}^{2+}\right]_{\mathrm{i}}$ increase was significantly reduced in the presence of 10 $\mu \mathrm{M}$ ruthenium red (RR), a broad TRP channel inhibitor (Fig. 5B). These results indicate the involvement of TRP channels in the membrane stretch-evoked responses in the developing neurons. To determine whether TRPV2 is a critical determinant for the membrane stretch-evoked responses, we constructed expression vectors of wildtype TRPV2 (WT-V2) and its dominantnegative form (DN-V2) (Nagasawa et al., 2007). We examined the effect of DN-V2 on the probenecid-activated WT-V2 currents in HEK293T cells (Fig. 5C,D). Coexpression of DN-V2 with WT-V2 significantly decreased probenecid-activated currents (from $171.5 \pm 25.2$ $\mathrm{pA} / \mathrm{pF}$ to $21.3 \pm 5.3 \mathrm{pA} / \mathrm{pF}, n=8$ ), confirming the dominantnegative effect, and the DN-V2 effect was found to be specific to TRPV2 among TRP channels known to be expressed in DRG neurons (Fig. 5E). cDNA of EGFP alone (as a control) or DNV2+EGFP was electroporated into DRG neurons from E12.5

\section{E12.5 spinal cord section}
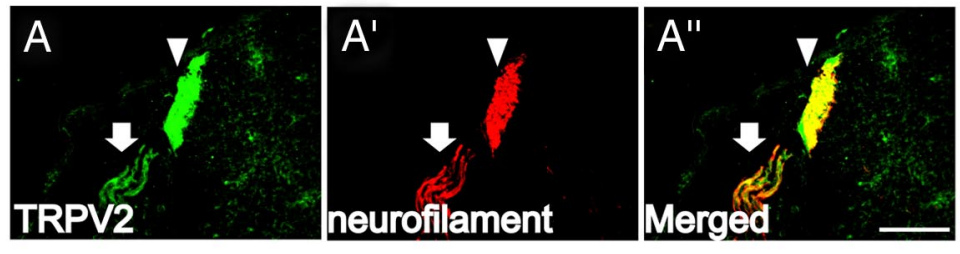

\section{DRG culture from E12.5}
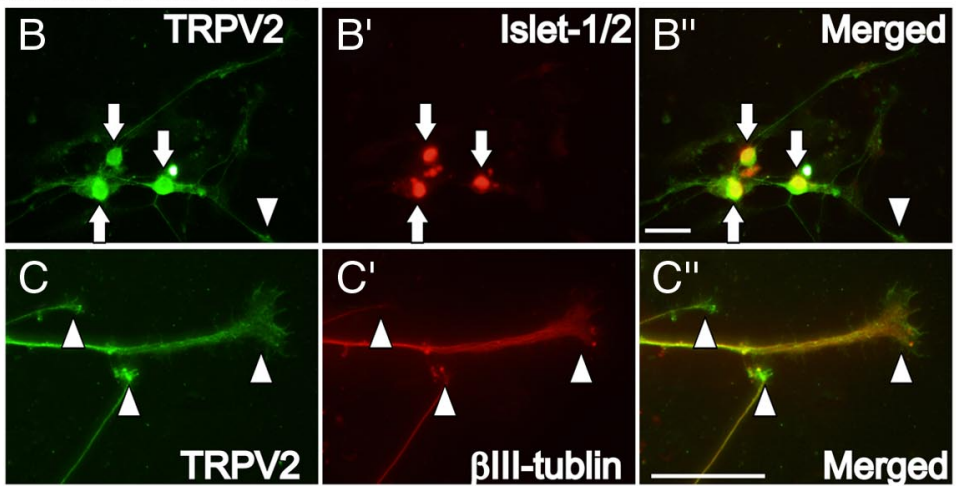

\section{motor neuron culture from E12.5}
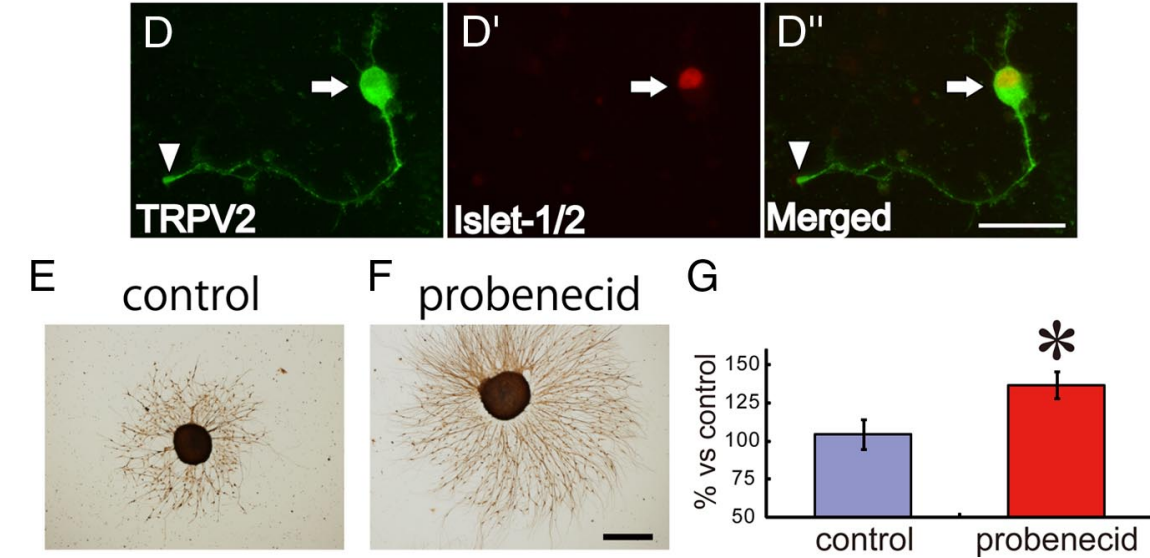

Figure 4. Expression of TRPV2 protein in developing sensory and motor neuron axons at E12.5. $A-A^{\prime \prime}$, Comparison of TRPV2 protein expression ( $\boldsymbol{A}$, green) with neuronal axon marker neurofilament $\left(\boldsymbol{A}^{\prime}\right.$, red) in mouse spinal cord at E12.5. TRPV2 protein accumulated in the dorsal horn (arrowheads in $A-A^{\prime \prime}$ ). We also observed TRPV2 expression on the axon shafts (arrows in $A-A^{\prime \prime}$ ). $\boldsymbol{B}-\boldsymbol{B}^{\prime \prime}$, Comparison of TRPV2 protein expression ( $\boldsymbol{B}$, green) with a neural marker, Islet1/2 ( $\boldsymbol{B}^{\prime}$, red), in cultured DRG neurons from E12.5 mouse embryos. TRPV2 proteins accumulated in cell bodies, which can be distinguished by Islet $1 / 2$ expression (arrows in $\boldsymbol{B}-\boldsymbol{B}^{\prime \prime}$ ). We also observed axonal TRPV2 expression in axon shafts and growth cones (arrowheads in $\boldsymbol{B}-\boldsymbol{B}^{\prime \prime}$ ). $\boldsymbol{C}-\boldsymbol{C}^{\prime}$, Comparison of TRPV2 protein expression ( $\boldsymbol{C}$, green) with an axon marker, $\beta$ III-tubulin $\left(\boldsymbol{C}^{\prime}\right.$, red), in cultured DRG neurons from E12.5 mouse embryos. TRPV2 protein was observed on the growth cone surface (arrowheads in $C_{,} C^{\prime}$ ). Some growth cones accumulated the TRPV2 protein (arrowheads in $\left.\mathbf{C}-\boldsymbol{C}^{\prime \prime}\right)$. $\mathbf{D}-\mathbf{D}^{\prime \prime}$, Comparison of TRPV2 protein expression ( $\boldsymbol{D}$, green) with a motor neuron marker, Islet1/2 ( $\boldsymbol{D}^{\prime}$, red), in cultured ventral spinal cord neurons from E12.5 mouse embryos. TRPV2 protein accumulated in motor neuron cell bodies, which can be distinguished by Islet1/2 expression (arrows in $\boldsymbol{D}-\boldsymbol{D}^{\prime \prime}$ ). Axonal TRPV2 expression was observed in axon shafts and growth cones (arrowheads in $\left.\mathbf{D}-\mathbf{D}^{\prime \prime}\right)$. $\boldsymbol{E}, \boldsymbol{F}, \mathrm{A}$ TRPV2 activator, probenecid $(100 \mu \mathrm{M})$, was applied to embryonic DRG explant cultures (from E12.5 embryos) for $2 \mathrm{~d}$. Explant cultures $(n=55-87)$ were fixed and stained with an anti- $\beta$ III tubulin antibody, and axon area percentage was quantified. G, Quantified axon area percentage of the probenecid-applied explant to the control value was shown with mean \pm SEM. Significant differences are represented as ${ }^{*} p<0.01$ versus control values. Scale bars: (in $\boldsymbol{A}^{\prime \prime}$ ) $\boldsymbol{A}-\boldsymbol{A}^{\prime \prime}, 200 \mu \mathrm{m}$; (in $\boldsymbol{B}^{\prime \prime}, \boldsymbol{C}^{\prime \prime}$, and $\boldsymbol{D}^{\prime \prime}$ ) $\boldsymbol{B}-\boldsymbol{D}^{\prime \prime}, 50 \mu \mathrm{m}$; (in $\left.\boldsymbol{F}\right) \boldsymbol{E}, \boldsymbol{F}, 1 \mathrm{~mm}$.

mouse embryos, and the neurons were cultured on silicon plates for $2 \mathrm{~d}$. Then, membrane stretch was applied to the cells. In cells expressing EGFP, $\left[\mathrm{Ca}^{2+}\right]_{\mathrm{i}}$ increased in response to membrane stretch; however, the $\left[\mathrm{Ca}^{2+}\right]_{\mathrm{i}}$ increase was significantly reduced in the DN-V2-expressing cells (Fig. $5 F$ ), suggesting that TRPV2 is a major component to respond to membrane stretch in developing neurons. Interestingly, the membrane stretch-induced $\left[\mathrm{Ca}^{2+}\right]_{\mathrm{i}}$ increase in DRG neurons was not significantly different 
A

HEK293T cells with WT-V2

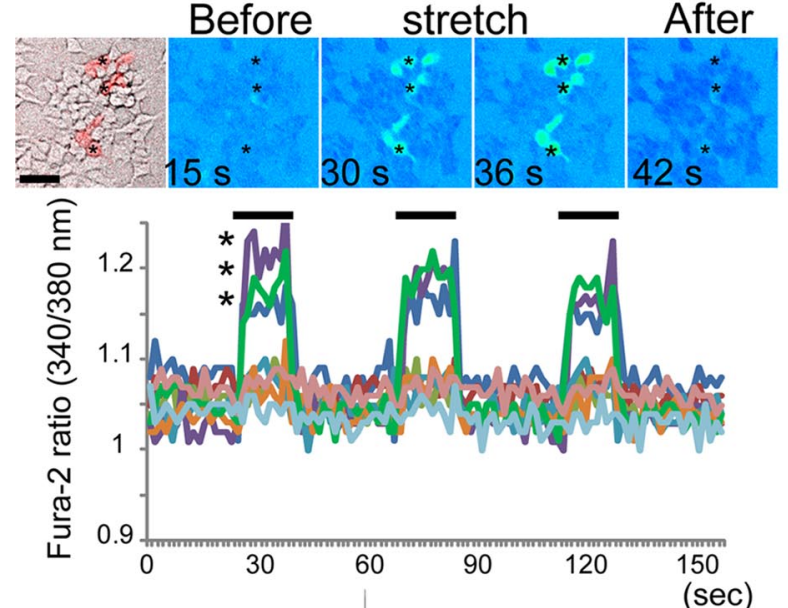

(sec)
B DRG neurons from E12.5
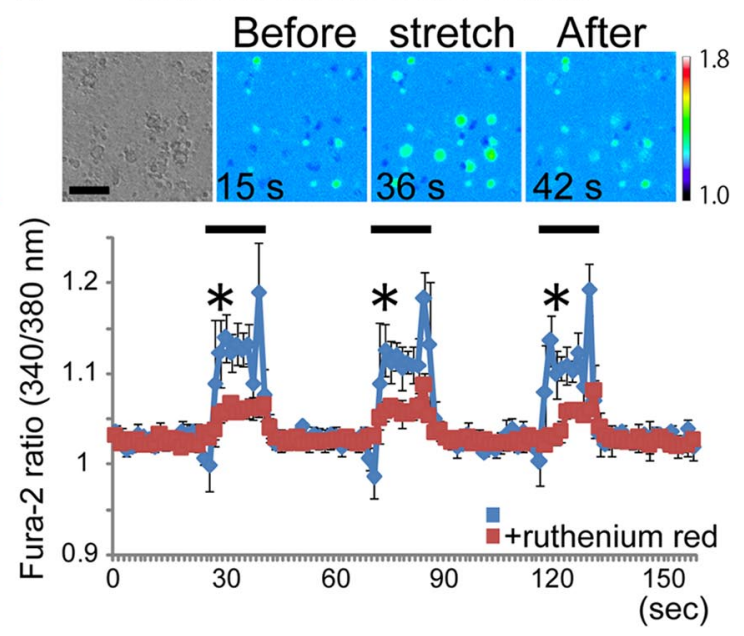

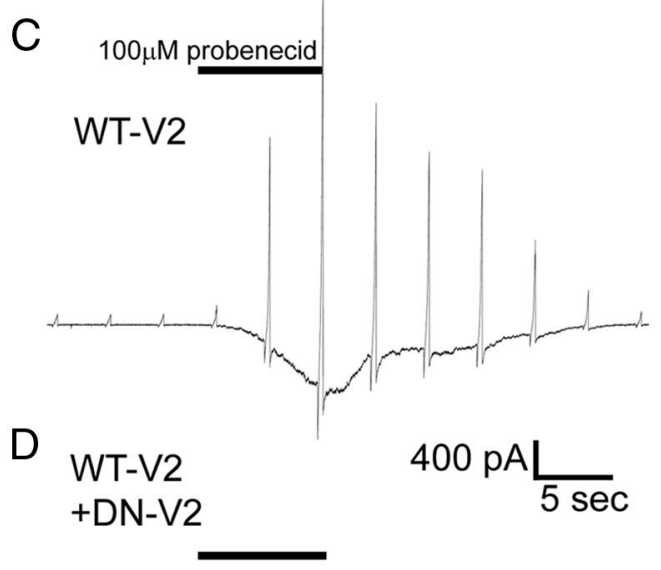

$\mathrm{E}$
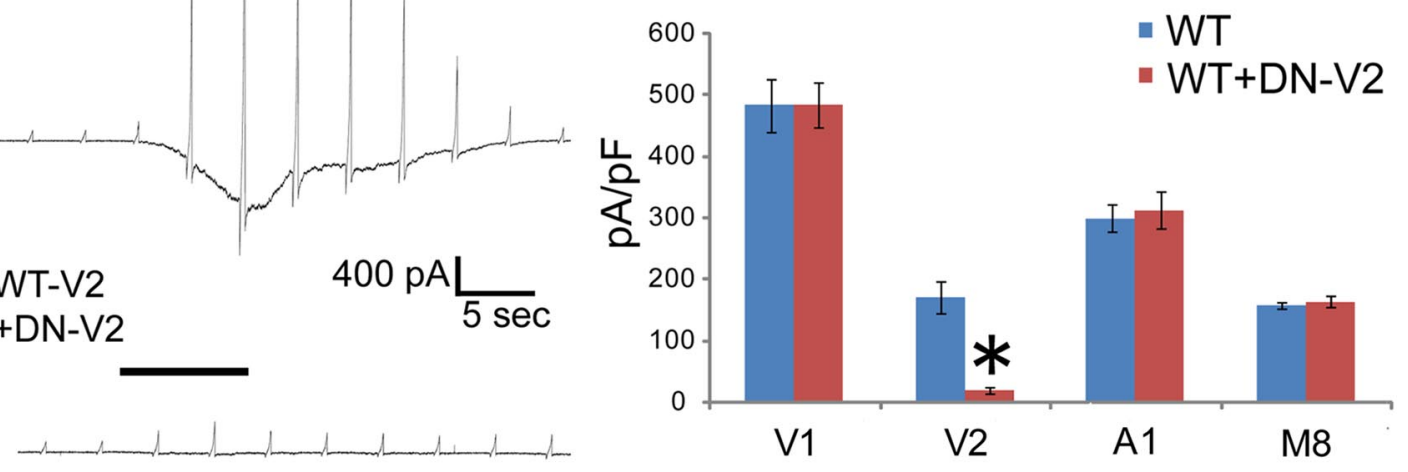

$\mathrm{F}$

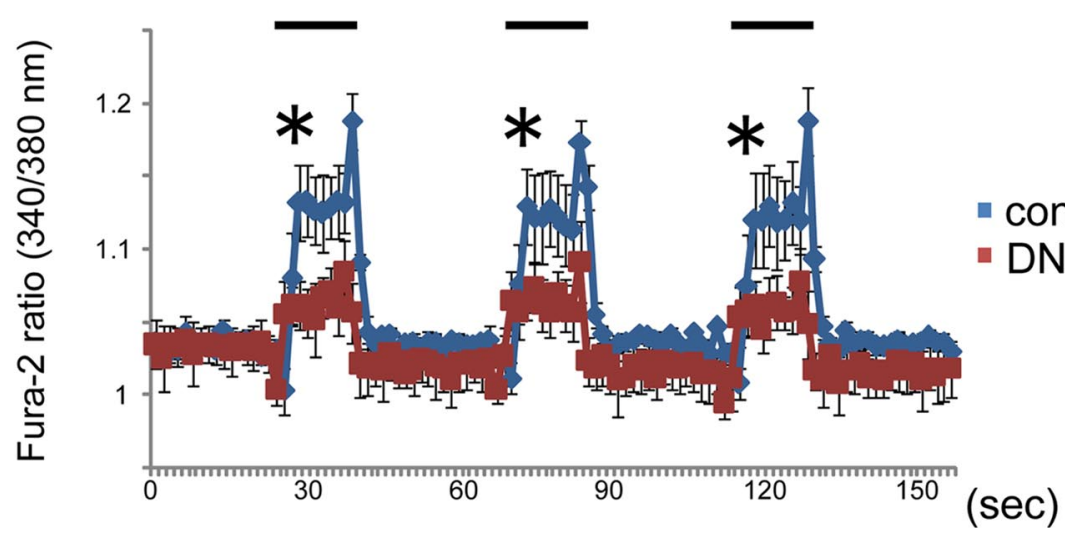

Figure 5. Membrane stretch activates endogenous TRPV2 in developing sensory neurons. A, HEK293T cells expressing WT-V2 were exposed to membrane stretch (102.8\% extension) for $15 \mathrm{~s}$ by the STREX machine during $\mathrm{Ca}^{2+}$ imaging. The red signals in the leftmost picture represent the WT-V2-transfected cells revealed by Ds-Red coexpression. Fura-2 ratio traces by symbols are from the cells indicated by the same symbols in the pseudocolor image. $\mathrm{Ca}^{2+}$ influx was observed only in the transfected cells (red cells) by $102.8 \%$ stretch. The representative traces were shown in the graph (both transfected and nontransfected cells). $\boldsymbol{B}$, Cultured DRG neurons (from E12.5 mouse embryos) were exposed to membrane stretch (102.8\% extension) as described previously. DRG neurons responded to the membrane stretch (blue); however, ruthenium red $(10 \mu \mathrm{m}$ ) mostly abolished the responses (red). $\boldsymbol{C}, \boldsymbol{D}$, Representative WT-V2 whole-cell currents activated by probenecid (100 $\mu \mathrm{m})$ without ( $(\boldsymbol{C})$ or with (D) coexpression of DN-V2 in HEK293 cells. E, Comparison of the effects of DN-V2 coexpression on the whole-cell current density of TRPV1 (V1), TRPV2 (V2), TRPA1 (A1), and TRPM8 (M8). HEK293T cells were transfected with cDNA of the indicated TRP channel alone or the channel with DN-V2, and TRP currents were activated by the application of $1 \mu \mathrm{m}$ capsaicin (V1), $100 \mu \mathrm{m}$ probenecid (V2), $150 \mu \mathrm{m}$ AITC (A1), or $100 \mu \mathrm{m}$ menthol (M8). The dominant-negative effect was observed only in cells expressing TRPV2.F, Cultured DRG neurons (from E12.5 mouse embryos) were electroporated with (DNA of EGFP alone or DN-V2 + EGFP. DRG neurons were exposed to membrane stretch (102.8\% extension). Control neurons (EGFP-positive cells shown in blue) responded to the membrane stretch; however, DN-V2 coexpression mostly abolished the responses (red). All values represent mean \pm SEM. Significant differences are represented as ${ }^{*} p<0.01$ versus control or WT values.

from that in HEK293T cells (Fig. 5A,F), although the TRPV2 expression level in HEK293T cells was $\sim 10$ times higher than that in DRG neurons revealed by immunoblot analysis (data not shown). These results suggest that HEK cells lacked TRPV2- binding proteins different from native neurons, because ion channel requires its binding partner to exert full function. For example, voltage-gated potassium channels, which have membrane topology similar to TRP channels, require $\beta$-subunits to 
form fully functional channels (Shi et al., 1996; An et al., 2000). Therefore, native neurons endogenously possess such environments for TRPV2 activation.

TRPV2 activation through membrane stretch leads to axon outgrowth in developing DRG and motor neurons To examine whether TRPV2 activity affects axon outgrowth of the developing DRG neurons, we expressed WT-V2 or DN-V2 ectopically using an electroporation method (Nakahira et al., 2006). Note that both cDNAs were subcloned into the pCAGIG vector (Matsuda and Cepko, 2004) to visualize neurons by EGFP fluorescence. Interestingly, WT-V2-overexpressing cells had significantly longer axons (WT-V2: $2432.5 \pm 637 \mu \mathrm{m}, n=121$ ) compared with control cells in DRG (EGFP alone: $1301.8 \pm 451.3 \mu \mathrm{m}, n=155)$ at 2 DIV (Fig. 6Aa,Ac,B). This WT-V2 effect was accompanied by an increase in $\left[\mathrm{Ca}^{2+}\right]_{\mathrm{i}}$ (Fig. 6C). Conversely, DN-V2 ectopic expression significantly reduced axon outgrowth (DNV2: $638.3 \pm 224 \mu \mathrm{m}, n=143$ ) compared with control cells (EGFP alone) (Fig. $6 A a, A e, B)$. This DN-V2 effect was similarly accompanied by a decrease in $\left[\mathrm{Ca}^{2+}\right]_{\mathrm{i}}$ (Fig. $6 C)$. We obtained similar results for the effects of TRPV2 expression on axon outgrowth in cultured motor neurons (supplemental Fig. $4 A, B$, available at www. jneurosci.org as supplemental material) like in DRG neurons. It should be noted that axon outgrowth observed in the DN-V2expressing cells was lower than that in control cells (Fig. 5B; supplemental Fig. 4B, available at www.jneurosci.org as supplemental material), suggesting that endogenous TRPV2 is constitutively activated in native cells to cause axon outgrowth.

We hypothesized that DN-V2 expression caused axon outgrowth reduction through decrease of $\mathrm{Ca}^{2+}$ influx by membrane stretch. This hypothesis was partially proven in another experiment in which we cultured DRG or spinal motor neurons from E12.5 mouse embryos with or without rotation. Rotation is expected to enhance mechanical force (shear stress) on the cell membrane by generating culture medium flow for $2 \mathrm{~d}$. Interestingly, rotation significantly enhanced axon outgrowth of EGFP-alone-expressing neurons compared with without rotation (Fig. 6A, B, DRG neurons; motor neurons are shown in supplemental Fig. $4 A, B$, available at www.jneurosci. org as supplemental material). Furthermore, the rotation effect on WT-V2-expressing neurons was significantly higher than that on EGFP-alone-expressing neurons (Fig. 6A, $B$, DRG neurons; motor neurons are shown in supplemental Fig. $4 A, B$, available at www.jneurosci.org as supplemental material). In contrast to EGFP-alone- or WT-V2-expressing neurons, DN-V2-expressing neurons did not significantly increase axon outgrowth by rotation (Fig. 6A, $B$, DRG neurons; motor neurons are shown in supplemental Fig. $4 A, B$, available at www.jneurosci.org as supplemen- control

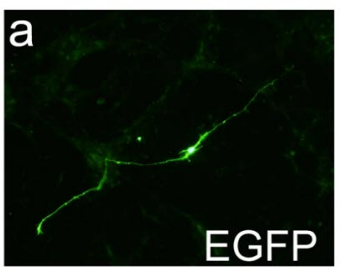

WT-V2

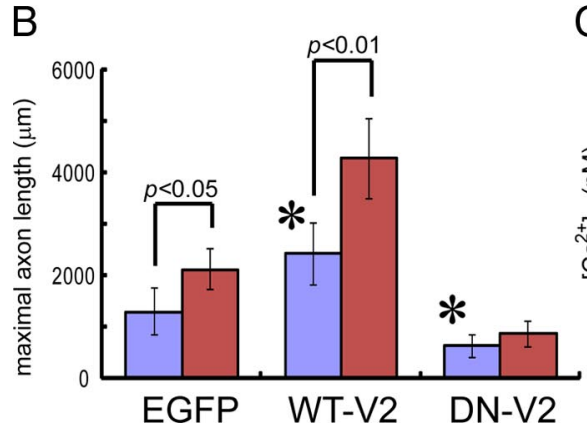

Figure 6. TRPV2 activation through membrane stretch promotes axon outgrowth in developing sensory neurons. $\boldsymbol{A}$, Representative images of cultured DRG neurons from E12.5 embryos (at 2 DIV); a control cell expressing EGFP (a), a cell expressing WT-V2 (c), and a cell expressing DN-V2 (e). All plasmid DNAs were incorporated by electroporation. Five independent cultures were examined expression significantly inhibited axon outgrowth $(\boldsymbol{e})$. To apply mechanical force on the cell membrane, we cultured dissociated DRG neurons electroporated with CDNA of EGFP alone $(\boldsymbol{b})$, WT-V2 (d), or DN-V2 (f), on a shaker (rotation). The rotation enhanced maximal axon length was quantified both in control (blue) and rotation (red) conditions. C, Comparison of intracellular calcium level both in control (blue) and rotation (red) conditions. All values represent mean $\pm S E M$. Significant differences are represented as ${ }^{*} p<0.01$ versus EGFP values or ${ }^{\#} p<0.05$ versus EGFP values.

tal material), suggesting that increase of mechanical force by rotation might elevate $\left[\mathrm{Ca}^{2+}\right]_{\mathrm{i}}$ through TRPV2 activation. In fact, rotation for $2 \mathrm{~d}$ was found to increase $\left[\mathrm{Ca}^{2+}\right]_{\mathrm{i}}$ in EGFP-or WT-V2-expressing DRG neurons, but not in DN-V2-expressing neurons (Fig. 6C), consistent with the proposed property of endogenous TRPV2. These results strongly indicate that TRPV2 is activated by membrane stretch and increases axon outgrowth through $\mathrm{Ca}^{2+}$ influx in developing DRG and spinal motor neurons.

TRPV2 regulates axon outgrowth in vivo during development The above results revealed that TRPV2 is an important regulator for axon outgrowth through membrane stretch in developing DRG and motor neurons (Figs. 4, 5; supplemental Fig. 4, available at www.jneurosci.org as supplemental material) under culture conditions (in vitro). To examine whether TRPV2 regulates axon outgrowth in vivo, we used an in ovo electroporation 
A
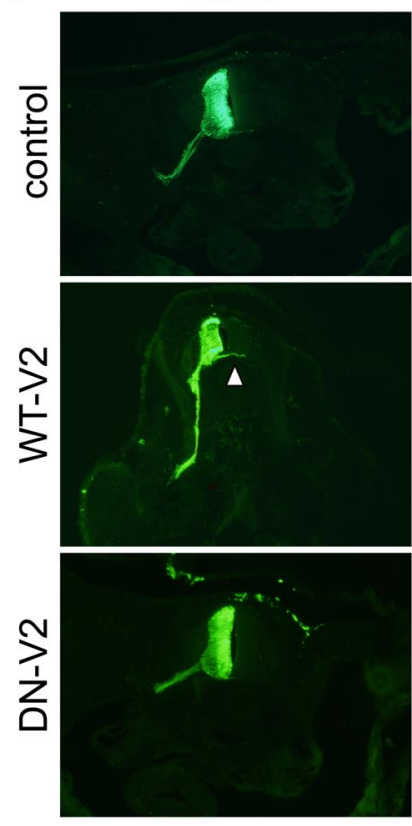

$\mathrm{B}$

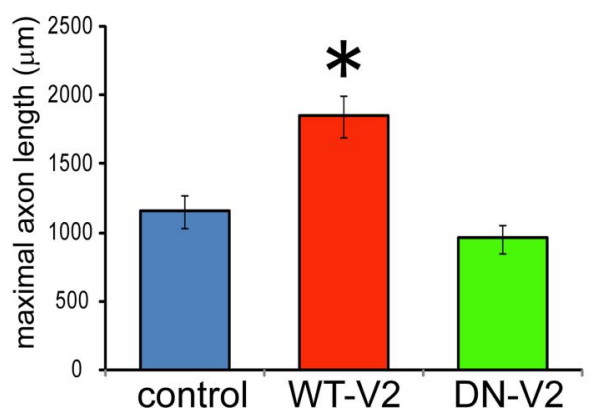

neurofilament
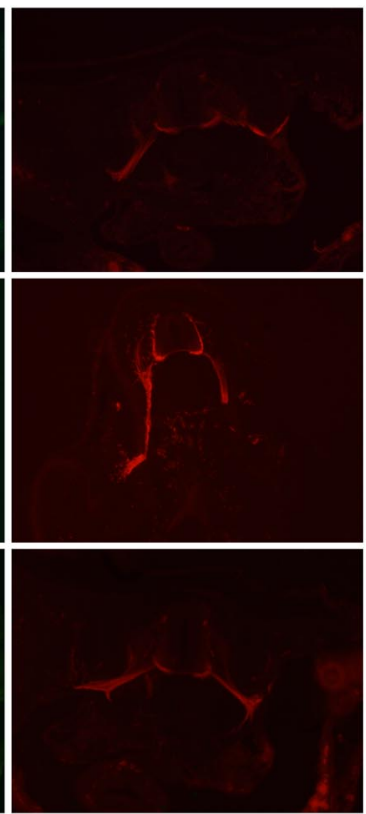

C

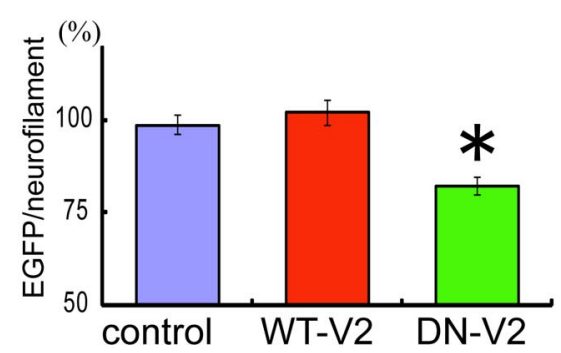

Figure 7. TRPV2 regulates axon outgrowth in chick embryos. $\boldsymbol{A}$, Representative images of motor neurons, which were identified by neurofilament expression (red) in chick embryos; a control spinal cord tissue expressing EGFP, a tissue expressing WT-V2, and a tissue expressing DN-V2. Arrowheads indicate commissural axons. All plasmid DNAs were incorporated by electroporation in ovo at HH 10 -14. After 1 d, chick embryos were fixed and tissue sections were prepared. Independent embryos (14-16) were examined. WT-V2 expression significantly enhanced axon outgrowth compared with EGFP. Scale bar, $1 \mathrm{~mm}$. $\boldsymbol{B}$, Maximal axon length in each embryo was measured and quantified. C, Ratio of GFP signal to neurofilament was quantified. All values represent mean \pm SEM. Significant differences are represented as ${ }^{*} p<0.01$ versus control values.

method (Itasaki et al., 1999). We electroporated cDNA of EGFP alone (as a control), WT-V2 (-IRES-EGFP) or DN-V2 (-IRESEGFP) into the left half of neural tubes at HH 10-14 chick embryos, in which axon formation from motor neurons has not been reported (Novitch et al., 2001; Vermeren et al., 2003). After $24 \mathrm{~h}$, embryos were fixed and spinal cord sections were prepared. The sections were colabeled with anti-GFP and anti-neurofilament $\mathrm{M}$ antibodies to identify motor neuron axons (Fig. 7A). Ectopic EGFP expression seemed not to have any deleterious effects on normal development when compared with nonelectroporated sides (Fig. 7A). To examine changes in axon outgrowth, we chose a maximal axon length from one embryo as representative data. Compared with the embryo expressing EGFP alone (1154.5 \pm $115.9 \mu \mathrm{m}, n=16$ ), WT-V2 overexpression significantly enhanced axon outgrowth $(1851 \pm 150.3 \mu \mathrm{m}, n=14)$ (Fig. $7 B)$ consistent with in vitro results (Fig. 6; supplemental Fig. 4, available at www. jneurosci.org as supplemental material). However, we did not detect any significant differences in maximal axon length between cells expressing EGFP alone and DN-V2 (958.5 $\pm 102.1 \mu \mathrm{m}, n=16)$ (Fig.
$7 B$ ), which differs from in vitro results (supplemental Fig. 4, available at www.jneurosci. org as supplemental material). We thought the quantifying method (maximal axon length) was not suitable to evaluate the DN-V2 effect. Therefore, we quantified the length ratio of neurofilament (native motor axon outgrowth) versus EGFP among cells expressing EGFP alone, WT-V2 or DN-V2, and detected significant differences between EGFP alone and DN-V2 (Fig. 7 $A, C$ ). These results indicate that $\mathrm{DN}-\mathrm{V} 2$-expressing neurons inhibited axon outgrowth consistent with our in vitro observations (Fig. 6; supplemental Fig. 4, available at www. jneurosci.org as supplemental material). Together, we confirmed that TRPV2 acts as an important regulator for axon outgrowth in vivo.

To further confirm the effect of TRPV2 on axon outgrowth, we generated shRNAexpression vectors for TRPV2 knockdown. One of the TRPV2 shRNAs (sh2) suppressed protein expression of TRPV2 [81.4\% reduction of negative control (NC) or scramble control (SC)] (Fig. 8A,B). Ectopic expression of sh2 in cultured embryonic DRG neurons significantly reduced axon outgrowth $(71.5 \%$ reduction of $\mathrm{NC}$ or SC) (Fig. $8 C, D$ ), consistent with our DN-V2 results (Fig. 6). Furthermore, in ovo electroporation of sh2 also reduced axon outgrowth compared with NC or SC overexpression (Fig. 8E,F). These results suggest that TRPV2 may play a role in axon outgrowth.

Reduction of extracellular $\mathrm{Ca}^{2+}$ concentration from $2 \mathrm{~mm}$ (physiological condition) to $0.15 \mathrm{~mm}$ (low $\mathrm{Ca}^{2+}$ ) inhibited enhancement of axon outgrowth through overexpression of WT-V2 in cultured DRG neurons (Fig. 8G,H), suggesting that $\mathrm{Ca}^{2+}$ influx through TRPV2 is necessary to enhance axon outgrowth.

\section{Discussion}

TRPV2 expression is restricted in sensory and motor neurons, and relates to regulation of axon outgrowth

In this study, we examined mRNA expression (by in situ hybridization), protein expression (by immunohistochemistry), channel activities (by $\mathrm{Ca}^{2+}$ imaging in dissociated neurons) and protein localization (by immunocytochemistry in dissociated cultured neurons). We successfully showed that TRPV2 is expressed in developing motor neurons in addition to sensory neurons (Figs. 1, 2). TRPV2 expression was broad (in immature neurons) in the sensory and motor neurons at early embryonic stages (Figs. 1, 2), after which expression became restricted to specific neuron subpopulations in postnatal stages; TRPV2 is expressed mainly in A $\delta$ fibers of adult DRG neurons (Caterina et al., 1999). Interestingly, thermo TRP channel expression varied in the developing DRG (TRPV2 at E10.5, TRPV1 at E13.5, and TRPM8 at E16.5) (Figs. 1, 2) (our unpublished observation). We propose a model in which immature neurons first express TRPV2 
at E10.5 (Figs. 1, 2), and then TRPV2positive neurons express TRPV1 or TRPM8 during neuronal maturation. Thus, TRPV2 could be a good marker for analysis of developmental processes in the sensory and motor neurons (Fig. 9). TRPV2 expression is a convenient landmark to examine transcriptional gene cascades in the developing DRG (Figs. 1, 2). At P0, TRPV2 expression still overlapped with TRPV1 and TRPM8 (Figs. 1,3 ), and did not overlap in the adult (our unpublished observation) as reported (Kobayashi et al., 2005). During postnatal stages, the sensory and motor axons extend according to increase in body size as well as embryonic stage; therefore, it might be required that TRPV2 colocalizes with TRPV1 or TRPM8 at P0 (Fig. 3) different from adult (Fig. 9).

TRPV2 is involved in axon outgrowth, consistent with its cellular localization in axon shafts and growth cones (Fig. 4). More importantly, we showed that TRPV2 has two distinct roles depending on the developmental stage: axon outgrowth regulation in the embryo (Figs. 6-8) and thermosensation and/or nociception in the adult (Caterina et al., 1999). This is the first observation that the embryonic thermo TRP channel has an embryonic stagespecific physiological role. We recently reported that TRPV4 in the hippocampus enhances neuronal activities through its activation at physiological body temperature (Shibasaki et al., 2007a), and TRPV4 in urinary bladder detects urinary volume increase (Mochizuki et al., 2009) while TRPV4 is known to act as a thermosensor in skin (Güler et al., 2002; Mandadi et al., 2009), implying that the same channel has two distinct functions depending on its location. Thus, thermo TRP channels might have other physiological roles in addition to sensing temperature based on location and timing of expression.

\section{Membrane stretch causes elevation of intracellular calcium through TRPV2 activation, and enhances axon outgrowth in developing neurons} We thought that TRPV2 might be activated by membrane stretch in extending axons because TRPV2 was reported to be a strong candidate for a mechanosensor (Muraki et al., 2003; O’Neil and Heller, 2005). It has already been reported that IGF-I promoted TRPV2 surface expression and activity (Kanzaki et al., 1999); however, IGF-I was not a strong candidate as a TRPV2 agonist in our culture system, because our culture medium lacked IGF-I. Therefore, we focused on the membrane stretch-activated property of TRPV2 (Muraki et al., 2003). We found that TRPV2 is abundant in developing growth cones and axon shafts (Fig. 4). Interestingly, ectopic

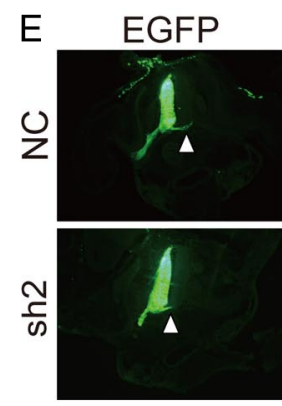

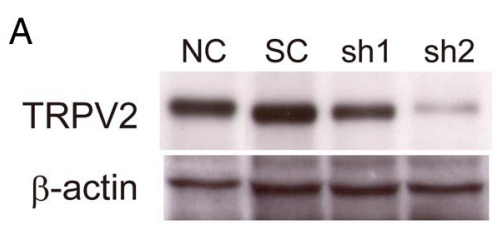
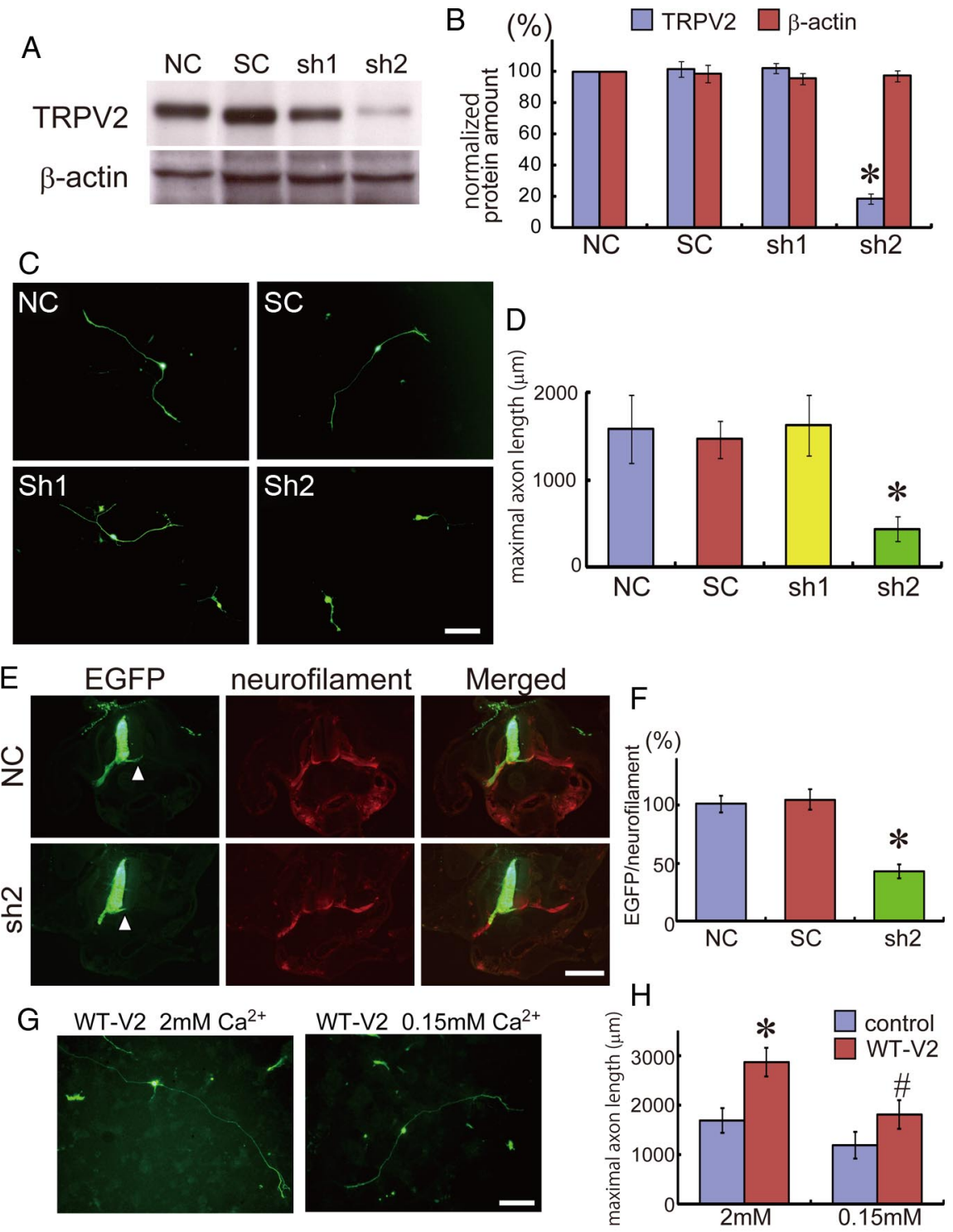

Figure 8. TRPV2 knockdown inhibits axon outgrowth both in vitro and in vivo. $\boldsymbol{A}$, Western blot analysis of the lysates from HEK 293 cells expressing TRPV2 with different shRNA-vector cotransfections. An anti-TRPV2 (TRPV2) (top) or anti- $\beta$-actin (bottom) antibody was used for immunoblotting. NC, Negative control (pBluescriptSKII); SC, cotransfection of scramble shRNA; sh1, cotransfection of TRPV2 shRNA\#1; sh2, cotransfection of TRPV2 shRNA\#2. B, Normalized amount of TRPV2 or $\beta$-actin protein $(n=4)$. All values represent mean \pm SEM. Significant differences are represented as ${ }^{*} p<0.01$ versus NC values. $C$, Representative images of DRG neurons, which were electroporated with EGFP. All plasmid shRNAs were incorporated into cultured DRG neurons by electroporation. Five independent cultures were examined $(n=72-113)$. $\boldsymbol{D}$, Average maximal axon length was quantified. Incorporation of shRNA\#2 significantly inhibited axon outgrowth. Significant differences are represented as ${ }^{*} p<0.01$ versus NC values. $\boldsymbol{E}$, Representative images of motor neurons, which were identified by neurofilament expression (red) in chick embryos; a control spinal cord tissue incorporated with NC and EGFP and a tissue incorporated with shRNA\#2 and EGFP. Arrowheads indicate commissural axons. All plasmid shRNAs were incorporated by electroporation in ovo at $\mathrm{HH} 10-14$. After $1 \mathrm{~d}$, chick embryos were fixed and tissue sections were prepared. Independent embryos $(9-12)$ were examined. $\boldsymbol{F}$, Signal ratio of GFP to neurofilament was quantified. Significant differences are represented as ${ }^{*} p<0.01$ versus NC values. $\boldsymbol{G}$, Representative images of DRG neurons expressing WT-V2 and EGFP, which were exposed to different $\mathrm{Ca}^{2+}$ concentrations [2 mm (physiological) or $0.15 \mathrm{~mm}$ (lower) condition]. $\boldsymbol{H}$, Maximal axon length in each condition was measured and quantified. Four independent cultures were examined ( $n=60-87)$. Significant differences are represented as ${ }^{*} p<0.01$ versus control with $2 \mathrm{~mm} \mathrm{Ca}^{2+}$ values or ${ }^{\#} p<0.01$ versus WT-V2 with $2 \mathrm{~mm} \mathrm{Ca}{ }^{2+}$. Scale bars: $\boldsymbol{C}$ and $\mathbf{G}, 200 \mu \mathrm{m} ; \boldsymbol{E}, 1 \mathrm{~mm}$.

expression of DN-V2 significantly reduced axon outgrowth in cultured embryonic sensory and motor neurons (Fig. 6; supplemental Fig. 4, available at www.jneurosci.org as supplemental material), suggesting constitutive activation of TRPV2 in native cells although the native ligand for TRPV2 has never been identified. When we increased mechanical stress by rotation culture 


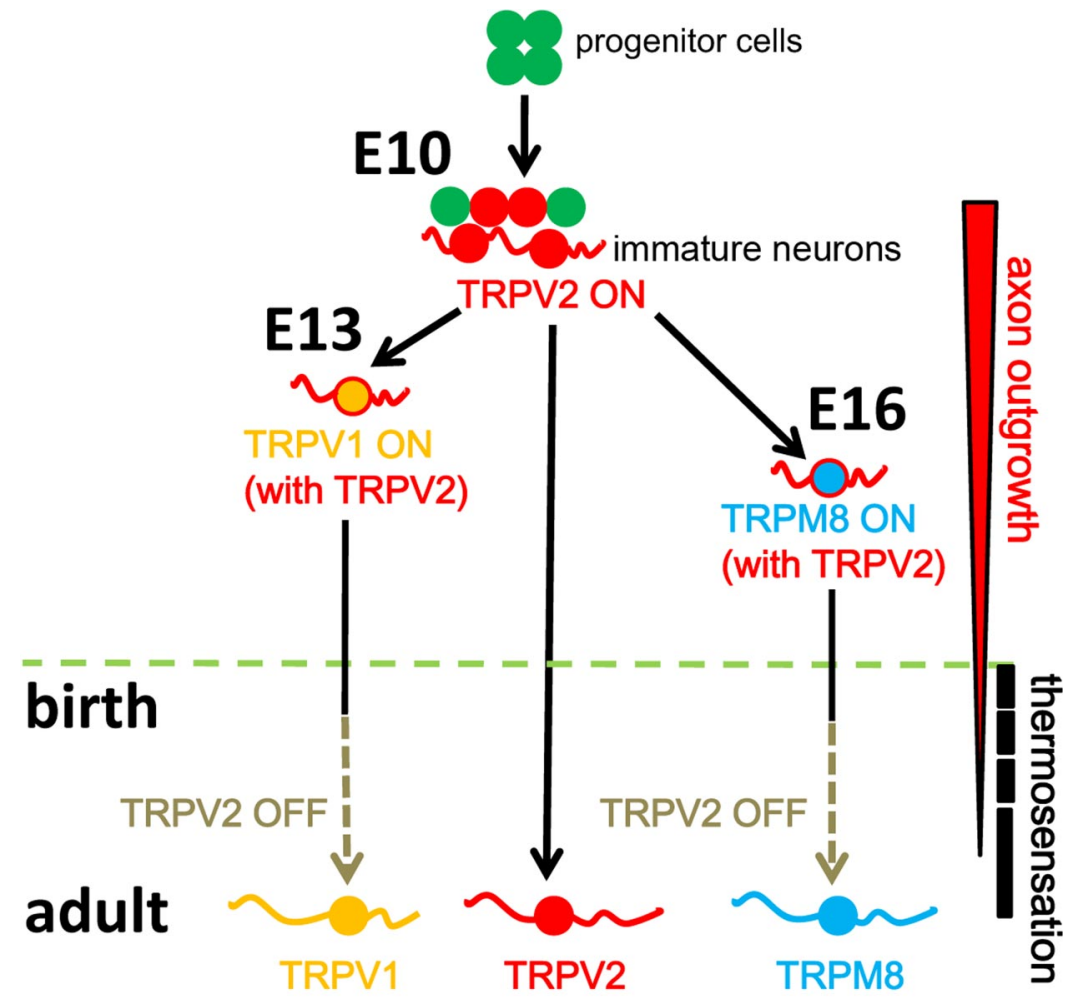

Figure 9. A new model of neuronal development with TRPV2 involvement. Green filled circles represent progenitor cells in DRG. TRPV2 expression starts in postmitotic neuronal precursors (shown as red filled circles) at E10 (Figs. 1-3). The TRPV2-positive immature neurons extend axons (shown by red lines), and axon outgrowth is positively regulated by TRPV2 (through membrane stretch) (Figs. 6-8). TRPV1-positive neurons (shown as a yellow filled circle) appear at E13.5, and then TRPM8-positive neurons (shown as a blue filled circle) appear at E16.5 (Fig. 1) (data not shown) during neuronal maturation. TRPV2 (shown by red lines) positively regulates axon outgrowth in TRPV1- or TRPM8-positive neurons until early postnatal stages. Then, TRPV2 expression disappears from TRPV1- or TRPM8-positive neurons. Finally, independent TRPV1, TRPV2, or TRPM8 expression is observed in adults. Thus, TRPV2 function dynamically changes from a regulator of axon outgrowth in embryo to a thermosensor (in adult).

condition (to add shear stress), axon outgrowth was significantly enhanced by $\mathrm{Ca}^{2+}$ influx through TRPV2 (Fig. 6). Furthermore, reduction of extracellular $\mathrm{Ca}^{2+}$ concentration inhibited the effects of TRPV2-overexpression on axon outgrowth (Fig. 8G,H). Together, we concluded that membrane stretch activates TRPV2 and enhances axon outgrowth. Thus, it is highly possible that membrane stretch is native stimulus for TRPV2 activation in developing neurons. How is membrane stretch induced in developing neurons? In our culture system, NGF and NT-3 are necessary for axon outgrowth. Since when we removed them from the culture medium, almost no axon outgrowth was observed (our unpublished observation). Thus, we currently consider that membrane stretch can be caused by naive axon outgrowth with NGF and NT-3 effects both in vitro and in vivo. Time lapse imaging of developing axon outgrowth would be useful to prove this hypothesis. Growth cones are supposed to repeat their extension and retraction during axon outgrowth. Such a mechanism might explain the restricted TRPV2 expression in DRG sensory and spinal motor neurons, because both neurons have to extend very long axons toward peripheral tissues, different from other spinal neurons.

We also demonstrated that the regulation of axon outgrowth by TRPV2 was observed in vivo (Figs. 6-8) in addition to in vitro. Our finding that membrane stretch elevates intracellular $\mathrm{Ca}^{2+}$, leading to axon outgrowth is quite novel. It has already been reported that $\mathrm{Ca}^{2+}$ influx through TRPC5 activation in restricted growth cone areas inhibited axon outgrowth in developing neurons (Greka et al., 2003), and that activation of NMDA receptors in growth cones also inhibited axon outgrowth (Baird et al., 1996). These observations apparently look contradictory to our findings. We would like to interpret the difference through the different expression patterns of the involved proteins. TRPC5 and NMDA receptors are abundant only in growth cones but not in axon shafts. On the other hand, TRPC1 activation by netrin was shown to induce $\mathrm{Ca}^{2+}$ influx in the entire axon including growth cones and axon shafts, and the $\mathrm{Ca}^{2+}$ influx enhanced axon outgrowth (Shim et al., 2005; Wang and Poo, 2005). This observation is very similar to the embryonic function of TRPV2 in our study (Figs. 5-8), whose expression was also observed in entire regions including soma, axon shafts, and growth cones (Fig. 4). These results suggest that the effects of $\mathrm{Ca}^{2+}$ influx on axon outgrowth might vary depending on the region in which $\mathrm{Ca}^{2+}$ influx is caused through channel activation. Together with the previous reports as described above (Baird et al., 1996; Greka et al., 2003; Shim et al., 2005; Wang and Poo, 2005), we have established a new concept in that membrane stretch activated axon outgrowth through TRPV2. Because we for the first time have identified that membrane stretch is a positive stimulus for axon outgrowth, in the future we can examine more detailed molecular mechanisms, such as whether other ion channels are also involved in membrane stretchinduced $\mathrm{Ca}^{2+}$-influx and/or what the important intracellular signalings are to enhance axon outgrowth after TRPV2 activation. Extrinsic factors have been extensively studied as stimuli regulating axon outgrowth/pathfinding or movement through changes in intracellular calcium/cyclic nucleotide (cAMP and cGMP) levels (Chilton, 2006). We emphasize that membrane stretch could also be a critical determinant for axon outgrowth. It has recently been reported that netrin 1 is transiently expressed in mouse dorsal spinal cord from E12.5 to E13.5 and that it inhibits axon projections into the dorsal mantle layer (Watanabe et al., 2006). Considering the TRPV2 expression profile (expression starts at E10.5) (Figs. 1, 2), transient netrin expression might affect both TRPV2 activity and axon outgrowth. Thus, axon outgrowth might be regulated through the combined activation of many $\mathrm{Ca}^{2+}$-permeable channels in a highly tuned manner in developing neurons. TRPV2 could be one important molecular modulator regulating axon outgrowth, suggesting that movement of growth cones and axon shafts by chemoattractive and/or chemorepulsive molecules produces proper membrane tensions to activate TRPV2 and regulates axon outgrowth during development. 


\section{References}

An WF, Bowlby MR, Betty M, Cao J, Ling HP, Mendoza G, Hinson JW, Mattsson KI, Strassle BW, Trimmer JS, Rhodes KJ (2000) Modulation of A-type potassium channels by a family of calcium sensors. Nature 403: 553-556.

Baird DH, Trenkner E, Mason CA (1996) Arrest of afferent axon extension by target neurons in vitro is regulated by the NMDA receptor. J Neurosci 16:2642-2648.

Bang S, Kim KY, Yoo S, Lee SH, Hwang SW (2007) Transient receptor potential V2 expressed in sensory neurons is activated by probenecid. Neurosci Lett 425:120-125.

Caterina MJ, Schumacher MA, Tominaga M, Rosen TA, Levine JD, Julius D (1997) The capsaicin receptor: a heat-activated ion channel in the pain pathway. Nature 389:816-824.

Caterina MJ, Rosen TA, Tominaga M, Brake AJ, Julius D (1999) A capsaicin-receptor homologue with a high threshold for noxious heat. Nature 398:436-441.

Chen CL, Broom DC, Liu Y, de Nooij JC, Li Z, Cen C, Samad OA, Jessell TM, Woolf CJ, Ma Q (2006) Runxl determines nociceptive sensory neuron phenotype and is required for thermal and neuropathic pain. Neuron 49:365-377.

Chilton JK (2006) Molecular mechanisms of axon guidance. Dev Biol 292: $13-24$.

Damann N, Voets T, Nilius B (2008) TRPs in our senses. Curr Biol 18:R880R889.

Greka A, Navarro B, Oancea E, Duggan A, Clapham DE (2003) TRPC5 is a regulator of hippocampal neurite length and growth cone morphology. Nat Neurosci 6:837-845.

Güler AD, Lee H, Iida T, Shimizu I, Tominaga M, Caterina M (2002) Heatevoked activation of the ion channel, TRPV4. J Neurosci 22:6408-6414.

Hjerling-Leffler J, Alqatari M, Ernfors P, Koltzenburg M (2007) Emergence of functional sensory subtypes as defined by transient receptor potential channel expression. J Neurosci 27:2435-2443.

Itasaki N, Bel-Vialar S, Krumlauf R (1999) 'Shocking' developments in chick embryology: electroporation and in ovo gene expression. Nat Cell Biol 1:E203-207.

Jordt SE, Bautista DM, Chuang HH, McKemy DD, Zygmunt PM, Högestätt ED, Meng ID, Julius D (2004) Mustard oils and cannabinoids excite sensory nerve fibres through the TRP channel ANKTM1. Nature 427: $260-265$.

Kanzaki M, Zhang YQ, Mashima H, Li L, Shibata H, Kojima I (1999) Translocation of a calcium-permeable cation channel induced by insulin-like growth factor-I. Nat Cell Biol 1:165-170.

Kobayashi K, Fukuoka T, Obata K, Yamanaka H, Dai Y, Tokunaga A, Noguchi K (2005) Distinct expression of TRPM8, TRPA1, and TRPV1 mRNAs in rat primary afferent neurons with adelta/c-fibers and colocalization with trk receptors. J Comp Neurol 493:596-606.

Komuro H, Rakic P (1993) Modulation of neuronal migration by NMDA receptors. Science 260:95-97.

Liebau S, Pröpper C, Böckers T, Lehmann-Horn F, Storch A, Grissmer S, Wittekindt $\mathrm{OH}$ (2006) Selective blockage of Kv1.3 and Kv3.1 channels increases neural progenitor cell proliferation. J Neurochem 99:426-437.

Mandadi S, Sokabe T, Shibasaki K, Katanosaka K, Mizuno A, Moqrich A, Patapoutian A, Fukumi-Tominaga T, Mizumura K, Tominaga M (2009) TRPV3 in keratinocytes transmits temperature information to sensory neurons via ATP. Pflugers Arch 458:1093-1102.

Matsuda T, Cepko CL (2004) Electroporation and RNA interference in the rodent retina in vivo and in vitro. Proc Natl Acad Sci U S A 101:16-22.

McKemy DD, Neuhausser WM, Julius D (2002) Identification of a cold receptor reveals a general role for TRP channels in thermosensation. Nature 416:52-58.

Mochizuki T, Sokabe T, Araki I, Fujishita K, Shibasaki K, Uchida K, Naruse K, Koizumi S, Takeda M, Tominaga M (2009) The TRPV4 cation channel mediates stretch-evoked Ca2 + influx and ATP release in primary urothelial cell cultures. J Biol Chem 284:21257-21264.

Muraki K, Iwata Y, Katanosaka Y, Ito T, Ohya S, Shigekawa M, Imaizumi Y (2003) TRPV2 is a component of osmotically sensitive cation channels in murine aortic myocytes. Circ Res 93:829-838.
Nagasawa M, Nakagawa Y, Tanaka S, Kojima I (2007) Chemotactic peptide fMetLeuPhe induces translocation of the TRPV2 channel in macrophages. J Cell Physiol 210:692-702.

Nakahira E, Kagawa T, Shimizu T, Goulding MD, Ikenaka K (2006) Direct evidence that ventral forebrain cells migrate to the cortex and contribute to the generation of cortical myelinating oligodendrocytes. Dev Biol 291:123-131.

Nakanishi S (1992) Molecular diversity of glutamate receptors and implications for brain function. Science 258:597-603.

Naruse K, Yamada T, Sokabe M (1998) Involvement of SA channels in orienting response of cultured endothelial cells to cyclic stretch. Am J Physiol 274:H1532-H1538.

Novitch BG, Chen AI, Jessell TM (2001) Coordinate regulation of motor neuron subtype identity and pan-neuronal properties by the bHLH repressor Olig2. Neuron 31:773-789.

O'Neil RG, Heller S (2005) The mechanosensitive nature of TRPV channels. Pflugers Arch 451:193-203.

Peier AM, Moqrich A, Hergarden AC, Reeve AJ, Andersson DA, Story GM, Earley TJ, Dragoni I, McIntyre P, Bevan S, Patapoutian A (2002) A TRP channel that senses cold stimuli and menthol. Cell 108:705-715.

Pollock NS, Ferguson SC, McFarlane S (2002) Expression of voltagedependent potassium channels in the developing visual system of Xenopus laevis. J Comp Neurol 452:381-391.

Shi G, Nakahira K, Hammond S, Rhodes KJ, Schechter LE, Trimmer JS (1996) Beta subunits promote $\mathrm{K}+$ channel surface expression through effects early in biosynthesis. Neuron 16:843-852.

Shibasaki K, Nakahira K, Trimmer JS, Shibata R, Akita M, Watanabe S, Ikenaka K (2004) Mossy fibre contact triggers the targeting of Kv4.2 potassium channels to dendrites and synapses in developing cerebellar granule neurons. J Neurochem 89:897-907.

Shibasaki K, Suzuki M, Mizuno A, Tominaga M (2007a) Effects of body temperature on neural activity in the hippocampus: regulation of resting membrane potentials by transient receptor potential vanilloid 4. J Neurosci 27:1566-1575.

Shibasaki K, Takebayashi H, Ikenaka K, Feng L, Gan L (2007b) Expression of the basic helix-loop-factor Olig2 in the developing retina: Olig2 as a new marker for retinal progenitors and late-born cells. Gene Expr Patterns 7:57-65.

Shibata R, Nakahira K, Shibasaki K, Wakazono Y, Imoto K, Ikenaka K (2000) A-type $\mathrm{K}+$ current mediated by the $\mathrm{Kv} 4$ channel regulates the generation of action potential in developing cerebellar granule cells. J Neurosci 20:4145-4155.

Shim S, Goh EL, Ge S, Sailor K, Yuan JP, Roderick HL, Bootman MD, Worley PF, Song H, Ming GL (2005) XTRPC1-dependent chemotropic guidance of neuronal growth cones. Nat Neurosci 8:730-735.

Story GM, Peier AM, Reeve AJ, Eid SR, Mosbacher J, Hricik TR, Earley TJ, Hergarden AC, Andersson DA, Hwang SW, McIntyre P, Jegla T, Bevan S, Patapoutian A (2003) ANKTM1, a TRP-like channel expressed in nociceptive neurons, is activated by cold temperatures. Cell 112:819-829.

Talavera K, Nilius B, Voets T (2008) Neuronal TRP channels: thermometers, pathfinders and life-savers. Trends Neurosci 31:287-295.

Tamura S, Morikawa Y, Senba E (2005) TRPV2, a capsaicin receptor homologue, is expressed predominantly in the neurotrophin-3-dependent subpopulation of primary sensory neurons. Neuroscience 130:223-228.

Trimmer JS (1998) Regulation of ion channel expression by cytoplasmic subunits. Curr Opin Neurobiol 8:370-374.

Vermeren M, Maro GS, Bron R, McGonnell IM, Charnay P, Topilko P, Cohen J (2003) Integrity of developing spinal motor columns is regulated by neural crest derivatives at motor exit points. Neuron 37:403-415.

Wang GX, Poo MM (2005) Requirement of TRPC channels in netrin-1induced chemotropic turning of nerve growth cones. Nature 434:898-904.

Watanabe K, Tamamaki N, Furuta T, Ackerman SL, Ikenaka K, Ono K (2006) Dorsally derived netrin 1 provides an inhibitory cue and elaborates the 'waiting period' for primary sensory axons in the developing spinal cord. Development 133:1379-1387.

Woolf CJ, Ma Q (2007) Nociceptors-noxious stimulus detectors. Neuron 55:353-364. 